Eighth IFC Conference on "Statistical implications of the new financial landscape" Basel, 8-9 September 2016

\title{
Gauging market dynamics using trade repository data: The case of the Swiss franc de-pegging ${ }^{1}$
}

Olga Cielinska, Andreas Joseph, Ujwal Shreyas, John Tanner, Michalis Vasios,

Bank of England 


\title{
Gauging market dynamics using trade repository data: The case of the Swiss franc de-pegging
}

Olga Cielinska ${ }^{1,}$ Andreas Joseph ${ }^{2}$ Ujwal Shreyas ${ }^{3}$, John Tanner ${ }^{4}$ and Michalis Vasios ${ }^{5}$

\begin{abstract}
The Bank of England ("the Bank") has access to some of the granular transaction level data resulting from EMIR trade reports. The velocity, granularity and richness of this dataset puts it in the realm of big data in the derivatives market, which brings with it its own set of challenges. These data have a number of potential uses in monitoring the market and helping to set policy. But these uses are only possible if the data are both accurate and complete on the one hand and we are able to analyse them effectively on the other. To help determine the status of these factors, we carry out a study of an external event to see how it was represented in the data. A suitable event was identified in the decision of the Swiss National Bank to discontinue the Swiss franc's floor of 1.20 Swiss francs per euro on the morning of 15 January 2015. This was expected to show a number of effects in the Swiss franc foreign exchange over-the-counter (FX OTC) derivatives market. The removal of the floor led to extreme price moves in the forwards market, similar to those observed in the spot market, while trading in the Swiss franc options market was practically halted. We find evidence that the rapid intraday price fluctuation was associated with poor underlying market liquidity conditions, in particular the limited provision of liquidity by dealer banks in the first hour after the event. Looking at longer-term effects, we observe an increased level of illiquidity, associated with an increased level of market fragmentation, higher market volatility and an increase in the degree of collateralisation in the weeks following the event. It is worth noting that whilst we analyse the impact of the event on the market, we are not commenting on the SNB's policy decision itself.
\end{abstract}

Keywords: Market Microstructure, FX Derivatives, Swiss franc, EMIR, Trade Reporting

JEL classification: G15 G18

\footnotetext{
1 olga.cielinska@bankofengland.co.uk

2 andreas.joseph@bankofengland.co.uk

3 ujwal.shreyas@bankofengland.co.uk

4 john.tanner@bankofengland.co.uk

5 michalis.vasios@bankofengland.co.uk
}

The views expressed in this paper are those of the authors, and are not necessarily those of the Bank of England or Financial Policy Committee members. Please address comments to the authors via e-mail. We are grateful to seminar participants at the Bank of England, the U.S. Office for Financial Research, the European Stability Risk Board, and the Cambridge-INET Institute conference on the microstructure of FX markets for helpful comments and suggestions. 


\section{Contents}

1 Introduction 3

$2 \quad$ Trade repository data $\quad 5$

$3 \quad$ The Swiss franc market $\quad 8$

$4 \quad$ Market impact from de-pegging the Swiss franc $\quad 14$

5 Conclusions 25

$6 \quad$ Refrences $\quad 26$

$7 \quad$ Appendix: Methodology for three tier network construction $\quad 27$ 


\section{Introduction}

\section{Background}

The OTC derivatives market has historically been decentralised and opaque. There has been no central source for trade information, for example on prices and trade sizes, either pre- or post-trade, let alone any information about counterparty identities and the network of exposures. This has been true not only for investors, but also for regulators. But this is changing.

In response to the 2008 global financial crisis, a number of reforms have been implemented to improve the functioning of OTC derivative markets, including increasing transparency. Most notably, in September 2009 G20 leaders agreed to make it mandatory for counterparties to derivatives transactions to report details of such contracts to trade repositories (TRs). ${ }^{6}$ This initiative, known as the reporting obligation, aimed to open the black box of OTC derivatives by making it possible for regulators to access, for first time, granular transactional data.

In the European Union (EU), the reporting obligation has largely been implemented by the European Market Infrastructure Regulation (EMIR). ${ }^{7}$ Under EMIR, all OTC and exchange-traded derivatives transactions undertaken by EU counterparties since August 2012 (or open at that point) have had to be reported by the following business day to a TR. The definition of counterparties covers primarily the activity of clearing houses, financial counterparties and non-financial counterparties that are EU legal entities.

The post-trade disclosure of derivatives transactions opens up a whole new range of possibilities for policy analysis, supervision and research. For example, the ability to observe trading activity and the network of exposures not long after the trades are executed could allow policy makers to identify the build-up of systemic risk within the financial system, as well as idiosyncratic risk to individual institutions for micro-prudential supervision purposes. But these uses require that the data are accurate and complete on the one hand and that we can analyse them effectively on the other. The evidence on these aspects is, however, limited so far, a gap we aim to fill. This is the first in-depth study in Europe to utilise the EMIR TR data relating to the FX market in an attempt to determine their strengths and limitations, as well as to showcase examples of policy analysis and research that can be conducted with them ${ }^{8}$.

We do so in two ways. First, we provide a first look at the second largest OTC derivatives market, the FX derivative market. By analysing its structure we gain some novel insights into a previously unexplored market. We then look at the market dynamics around a recent policy event that was not anticipated by FX market

\footnotetext{
${ }^{6}$ The 2009 G20 reform agenda also included the increase in pre-trade transparency by the introduction of multilateral trading venues for certain derivative markets as well as reducing risk in the market through measures including the push towards central clearing and the exchange of collateral more generally. ${ }^{7}$ Regulation (EU) No 648/2012 of the European Parliament and of the Council, of 4 July 2012 on OTC derivatives, central counterparties and trade repositories; commonly known as "EMIR".

${ }^{8}$ Another study that uses the EMIR TR data is the September 2016 ESRB published Occasional paper no. 11: Shedding light on dark markets: First insights from the new EU-wide OTC derivatives dataset, which provides a description of the data.

(https://www.esrb.europa.eu/pub/pdf/occasional/20160922_occasional_paper_11.en.pdf?c067e1f68ae0fe $23925 b 88 c 613 c 546 a 8)$
} 
participants: the decision by the Swiss National Bank (SNB) to remove the Swiss franceuro exchange rate floor at 10:30 AM CET on 15 January 2015. The exogenous nature of this event and the speed and scale of subsequent intraday currency movements makes it well-suited for an event-study analysis. It is worth noting that whilst we analyse the impact of the event on the market, we are not commenting on the SNB's policy decision itself.

For such an analysis to be meaningful, it would require the use of transaction data and information about counterparty identities in order to analyse how different market players responded to the removal of the floor. This is exactly the type of information contained in the EMIR data. TR data provide us with a unique insight into the functioning of the FX derivatives market, going significantly beyond what other data sources can tell us. To fully exploit this highly granular trade-level data we make use of analytical techniques from empirical finance and network science.

\section{Analytical Results}

Of all the reported transactions to European TRs, the Bank is entitled to see trades where one of the below criterion are satisfied, i.e. at least one of the counterparties is a UK entity, the trade is cleared by a UK CCP, and the asset traded is either denominated in Sterling or has a UK underlying. In our analysis we use reports for outright forwards, FX swaps (the forward leg) and options, which we obtained from the largest trade repository, DTCC. Given the focus on the SNB announcement, we limit our analysis to just the Swiss franc (CHF) segment of the market. In practice, this means that we only look at reports where one leg of the trade is denominated in Swiss franc.

The raw data used in the paper included about 100 million reports consisting of new FX derivative trades (not all of which were unique) as well as valuation updates and 300 million outstanding FX positions between November 2014 and March 2015. The length of the period was chosen to cover the Swiss FX market before and after the de-pegging event so that meaningful comparisons would be possible. After filtering and cleaning we were left with about 400,000 new CHF trades executed by over 9,000 counterparties and 3 million outstanding CHF positions. Despite using data from only one TR and other limitations ${ }^{9}$, we estimate that we are able to observe more than half of the market (by comparing with OTC derivatives data from BIS (2015), perhaps because of the role of London as a global financial centre for FX markets. This ensures to some extent that any observed patterns in the data reflect the whole global market.

Before conducting any in-depth analysis, we report some basic statistics. The Swiss franc market is a medium-sized FX market. We see trades accounting for around US $\$ 100$ billion notional traded daily, of which more than three quarters are forwards (outrights and the forward leg of FX swaps) and the remainder are options. The average maturities are short ( $<1$ year) and we observe some bunching around three-, six-, nine- and twelve-month maturities. The most actively traded currency pair is the US dollar/Swiss franc (USDCHF) followed by the Euro/Swiss franc (EURCHF). The market structure is highly concentrated, with trading by a small number (about 11) of big dealers accounting for more than $90 \%$ of the market, of which almost half represents interdealer activity. This is consistent with the commonly held view that OTC trading is dominated by a few large dealers.

\footnotetext{
9 The data does not include any trades for the counterparty pairs such as Swiss - Swiss, US-US and Swiss-US
} 
We look at the structure of the Swiss franc market in more detail using network topology techniques, which allows us to identify three distinct segments of the market: an inner core of big liquidity providers, an outer-core of medium-sized active counterparties, and a periphery of small end-users, who are characterized by more directional trading. We demonstrate how the three-tier structure can have interesting implications for network stability and fragmentation and the analysis of liquidity provision, which we regard as a methodological contribution of the paper.

We next move to the analysis of the de-pegging, first, by reconstructing the event using the available transaction data and analysing the response of different market counterparties to the SNB announcement, and, second, by looking at the longer-term impact on market liquidity, trading positions and the structure of the network.

\section{Intraday analysis:}

We provide evidence of a rapid V-shaped price movement in the EURCHF OTC forward market similar to the one observed in the spot market. The Swiss franc appreciated by nearly $41 \%$ against the euro in the first 20 minutes after the announcement, before stabilising at around 1.05 (an appreciation of around 14\%). We find that in the first 15 minutes after the announcement, the provision of liquidity was limited, as evidenced by the low dealer-to-client trading, the small average trade size of EURCHF forwards trades, and the fact that dealers were initially buying Swiss francs, which suggested they were consuming liquidity instead of providing it. After 15 minutes, dealers gradually started to play the role of liquidity provider, even if this activity was potentially loss-making as it coincided with the Swiss franc price reversal (i.e. depreciation). Collectively, our analysis provides some evidence that the rapid Vshaped Swiss franc price fluctuation on 15 January was associated with underlying market liquidity conditions. This demonstrates the value of the granular nature of the TR data and that it can be used to analyse intraday market dynamics.

\section{Longer term impact:}

Looking at the two-and-a-half-month period following the announcement we find that: a) the trading network became more fragmented compared to a similar period before the announcement, in part due to a reduction in inter-dealer activity, b) liquidity in the market decreased, indicated by an increase in measures of volatility and illiquidity as well as a decrease in average trade sizes, and c) the amount of collateral exchanged by the different counterparties increased. The more volatile prices in the new regime might explain some of the drop in liquidity, due to a higher degree of information asymmetry and inventory holding costs, both of which are expected to have impaired market liquidity. The drop in liquidity might also relate to the finding that the trading network has become more fragmented, thus making it harder for dealers to match supply and demand.

\section{Trade Repository Data}

\section{Reporting framework}

In September 2009, in response to the financial crisis G20 Leaders agreed that OTC derivatives transactions should be reported to trade repositories so that they could be collected and analysed by the respective regulatory authorities. The trade reporting framework was part of a larger package of reforms aimed at mitigating systemic risk, improving transparency in an opaque market and protecting against 
market abuse. This reporting obligation has been implemented in different ways across jurisdictions, e.g. EMIR in the EU and the Dodd-Frank Act in the U.S. In Europe, trade reporting to the TRs began in February 2014.

\section{The structure of the data and cleaning process}

We analyse five months of OTC FX data between November 2014 and March 2015, provided by DTCC. The data contain reports for forwards and options, with the forward category including both outright forwards and the forward leg of FX swaps. These two types of products account for about $80 \%$ of the global FX OTC derivatives market (BIS 2015). The missing 20\% consists of mainly currency swaps, which are reported separately as interest rate derivative products, which we did not analyse for this study. We do not observe spot transactions, since these do not fall under EMIR reporting requirements. ${ }^{10}$

The TR data can be broadly divided into two types of reports: a) activity reports, which contain trade information on flows, for example new trades, modifications, and valuation and cancellation updates; and b) state reports, which contain trade information on stock, i.e. all end-of-day outstanding transactions between individual counterparties. The state and activity reports are generated each day and are available for the Bank to see with a one-day lag. ${ }^{11}$ The DTCC TR data, the one used for this study contained more than 100 fields, of which 85 were EMIR fields and the remaining were TR introduced fields. These fields include information on trade characteristics and more importantly counterparty identities. However, not all of them contain information relevant to FX derivatives

Given the decentralised nature of OTC markets, EMIR data come with certain limitations and data processing can be time consuming and challenging. We went through several stages of data cleaning to make the raw data suitable for analysis. The steps involved filtering, deduplication and group consolidations, partial outlier detection and the dropping of missing values. The process of filtering and deduplication is described in Chart 1 . The raw activity and state reports contained about 100 million and 300 million rows of trades, respectively between November 2014 and March 2015, not all of which contained new trade information or involved the Swiss franc. After filtering the data as per the steps outlined in Chart 1 , we were left with a sample of 380,000 activity reports and around 3 million state reports. Importantly, these are single records for each relevant trade, thus avoiding doublecounting ${ }^{12}$ that could have biased our trading activity analysis.

The TR data used for the analysis might introduce certain biases due to the fact that we make use of data from just one TR and the Bank is entitled to only a subset of trades where one of the counterparties is an UK entity. ${ }^{13}$ To get a better idea of the degree of potential bias we compared the aggregates obtained from our data to

\footnotetext{
10 Nonetheless, we did get access to anonymised spot transactions executed on 15 January from EBS BrokerTec, an electronic FX platform provider. We used this data to visualize the intraday price movement in the spot market on the event day.

11 EMIR requires reports to be made to TRs either on the day of an event or the day after. The resulting data is made available to the Bank on the day after it was reported. The precise timing of the reporting was not significant to this analysis because it was carried out well after the event being analysed.

12 A) EMIR is a double-sided reporting regime, so the Bank would see two copies for a single executed trade when both the counterparties are UK entities (and, in this case, where they are both reporting the trade to DTCC). B) As per the EMIR regulation, the activity reports could contain several copies of the same trade to reflect each of the modification, correction and valuation updates.

${ }^{13}$ The FX market being largely uncleared means that the jurisdiction of the counterparty is the primary reason why the Bank would see a particular report.
} 
BIS (2015) OTC derivative statistics. According to DTCC EMIR TR data available to the Bank on 31 December 2014 there were US\$0.9 trillion of Swiss franc forwards and swaps outstanding, as well as US\$0.8 trillion Swiss franc options. According to semiannual BIS data, on 31 December 2014 the notional outstanding of Swiss franc OTC FX derivatives was about US $\$ 4.2$ trillion. ${ }^{14}$ Of this, US $\$ 2.1$ trillion was accounted for by forwards and swaps, and US $\$ 0.9$ trillion by options. ${ }^{15}$ Although there might be some noise in this comparison due to differences in methodology, the findings in Chart 2 indicate that we see a significant portion of the global Swiss franc FX derivatives, especially in options, as a result of London's status as a global centre for FX trading.

Summary of the data cleaning process for activity and state reports

Chart 1

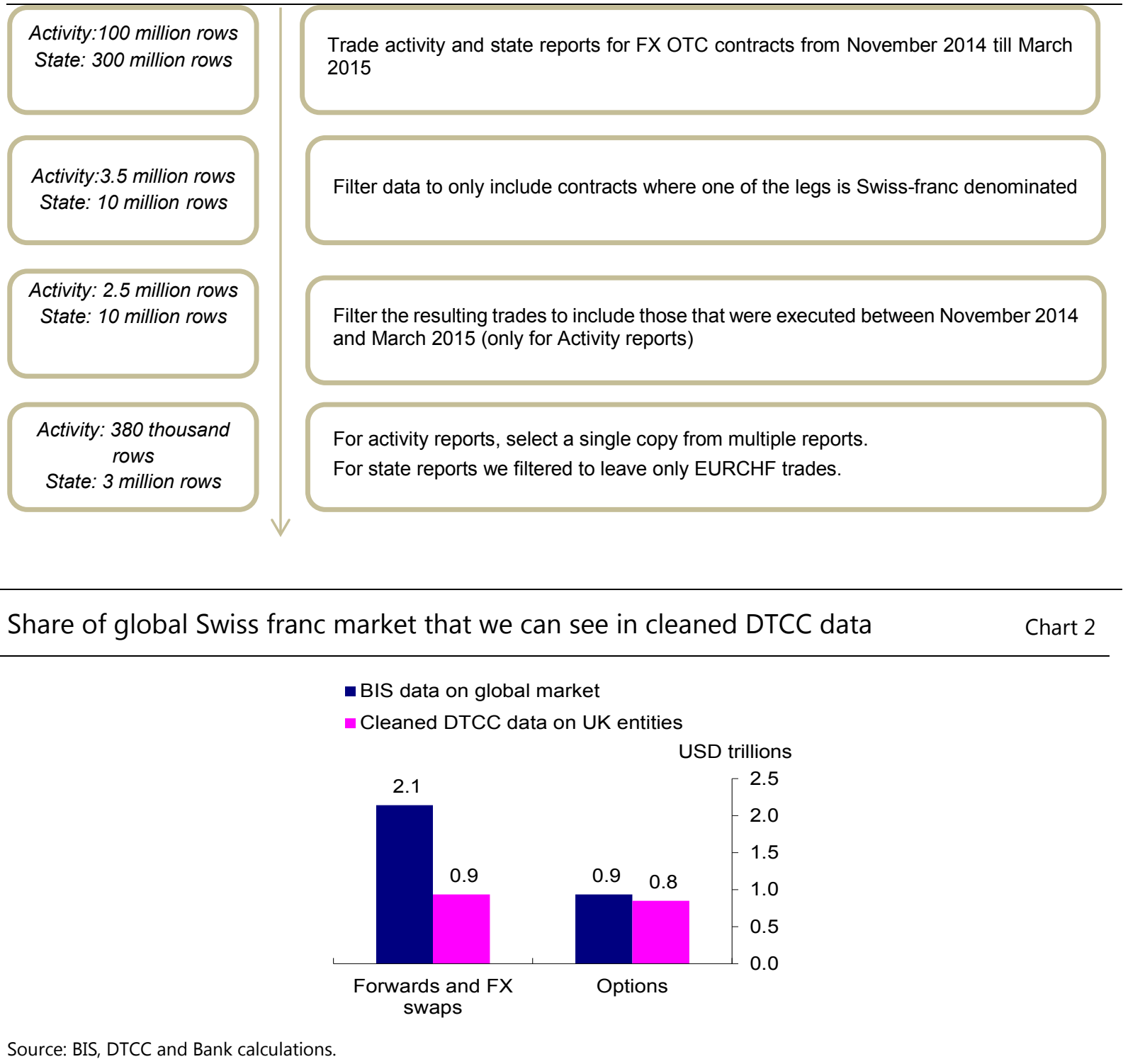

14 This made up 5.5\% of the whole USD 75.9 trillion OTC FX derivatives market, which in turn accounts for $12 \%$ of overall OTC derivative activity measured by notional size.

15 According to BIS estimates, its semi-annual survey captures $90 \%$ of global OTC derivatives market. 


\section{The Swiss franc market}

\section{Summary statistics}

In this section we provide a first insight into the Swiss franc segment of the OTC FX derivatives market using new trades executed between November 2014 and March 2015, as well as data on counterparties' positions.

- The size of the market. The total outstanding notional of Swiss franc derivatives in our data on 31 December 2014 was US $\$ 900$ billion and US $\$ 800$ billion for forwards and options, respectively (Chart 2). We observe nearly 3,700 Swiss franc trades per working day, with an average daily traded notional of US $\$ 118$ billion. $88 \%$ of notional represented trading in forwards and the rest in options (Chart 3).

- Currencies. The majority of Swiss franc derivatives trades we see were against the US dollar, accounting for $82 \%$ of all Swiss franc forward trades and $64 \%$ of all options trades in the market (Charts 4 and 5). When looking at the Swiss franc trades against the euro, a greater share is accounted for by options i.e. of all option trades $33 \%$ were against the euro compared to $14 \%$ for forwards. This seems intuitively sensible if some of the market participants wanted to position/hedge against sharp changes in the Euro to Swiss franc exchange rate.

- Maturities. The average maturity of forwards is very short. Over half of all forwards have a maturity of no more than a week, and over $96 \%$ no more than four months (Chart 6). The maturity for options is slightly longer, although the most common maturity for options is between one week and two months. We can observe some bunching around three-, six-, nine- and twelve-month maturities (Chart 7). This pattern is indicative of higher liquidity at certain tenors, in line with market convention.

- Counterparties. Chart 8 decomposes traded notional by counterparty ${ }^{16}$. G16 ${ }^{17}$ dealers make up a significant majority of trading in both forwards and options (75\% and $80 \%$, respectively). The rest of trading in the forwards market is split between banks, buy-side firms, service providers to institutional clients, corporates and others. Trading in the options market is more homogeneous, with most non-dealer activity coming from hedge funds. In fact, trading in options makes up 37\% of all Swiss franc FX derivative activity done by hedge funds, by far the highest share of any of our categories (Chart 9). One potential reason for this could be that speculative activity was more likely to be present in the options market, while hedging activity by corporates and various funds was done in the forwards market. It is worth mentioning, that although the percentage of 'Others' is large, these entities are typically very small and collectively account for a relatively small fraction of the traded notional in the Swiss franc market - around $5 \%$.

\footnotetext{
16 Majority of the sector classification used for the analysis was carried out manually; hence some of the classification would be imprecise. However, this has been invaluable to bring out some of the broader trends in the market.

17 The biggest 16 dealers in our subset of the TR data arranged in alphabetical order are: Bank of America, Barclays, BNP Paribas, Citigroup, Crédit Agricole, Credit Suisse, Deutsche Bank, Goldman Sachs, HSBC, JP Morgan, Morgan Stanley, Nomura, Royal Bank of Scotland, Société Générale, Standard Chartered and UBS. This choice is not arbitrary on our part as most of these banks are also classified as "Participating Dealers" in the OTC Derivatives Supervisors Group, chaired by the New York Fed: https://www.newyorkfed.org/markets/otc derivatives supervisors group.html
} 
Daily volume of notional traded in the Swiss franc market between November 2014 and March 2015 split by product type

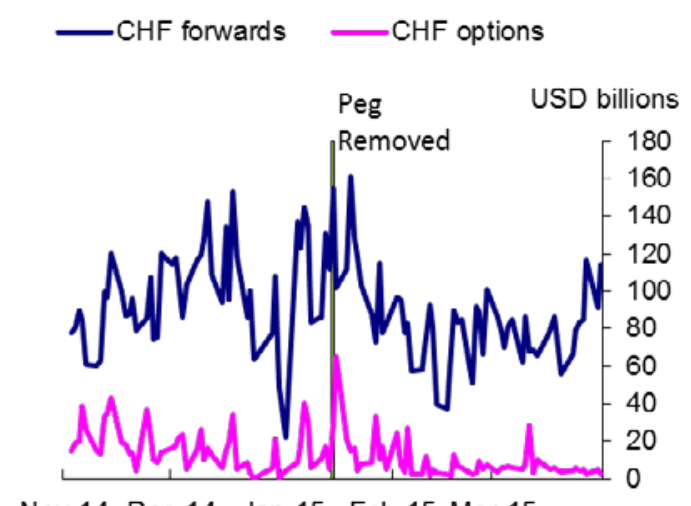

Nov-14 Dec-14 Jan-15 Feb-15 Mar-15

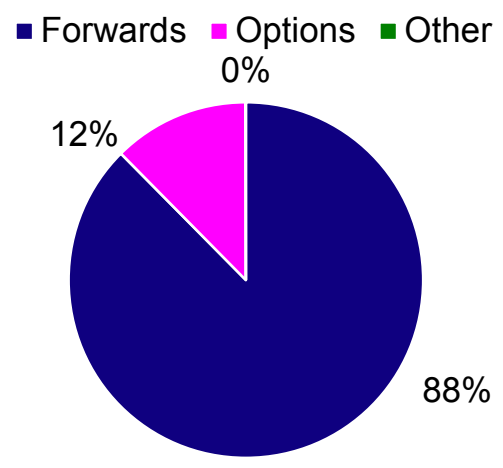

Source: DTCC and Bank calculations.
Volume of Swiss franc option trades Chart 4 split by counter currency

\section{trades split by counter currency}

- USD $=$ EUR - GBP $\approx$ JPY $\approx$ Other $2 \% 1 \% 1 \%$

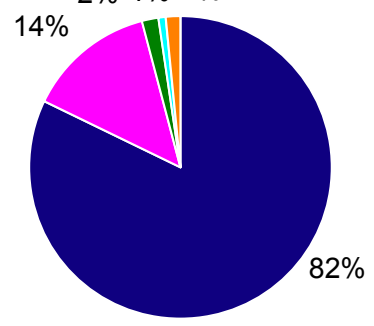

Source: DTCC and Bank calculations.

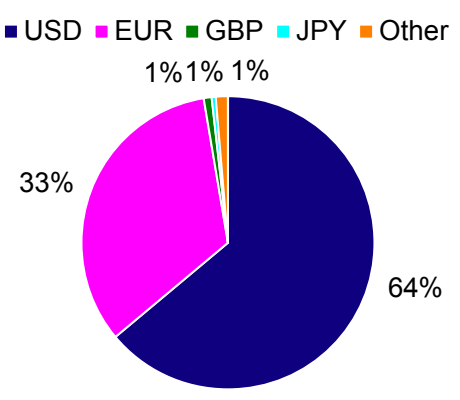

Source: DTCC and Bank calculations.
Maturity distribution of Swiss franc forwards trades between November 2014 and March 2015
Maturity distribution of Swiss franc options trades between November Chart $6 \quad 2014$ and March 2015
Number of trades (thousands)

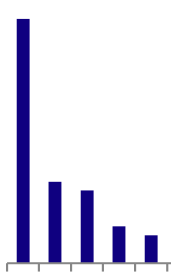

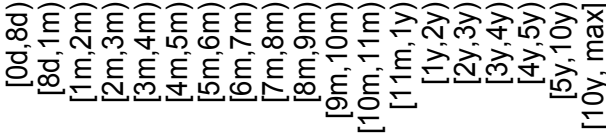

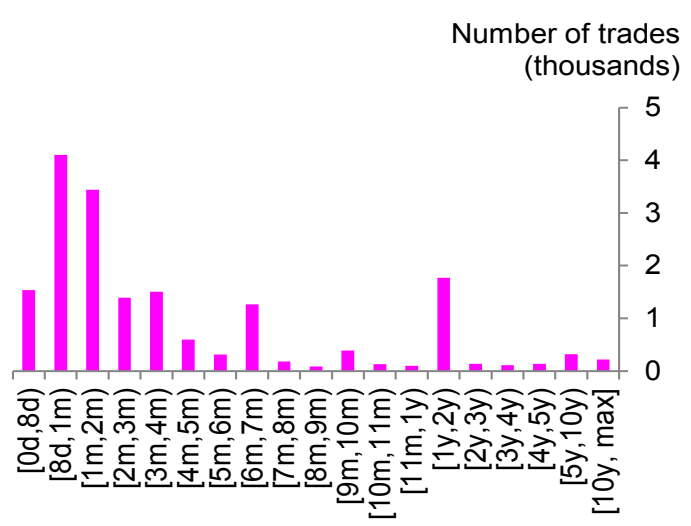

Source: DTCC and Bank calculations. 


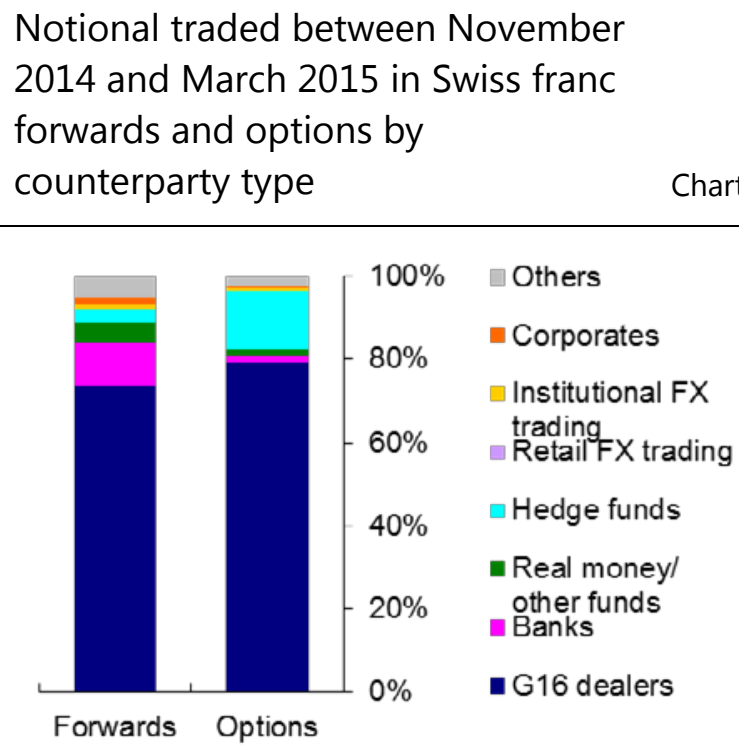

Source: DTCC and Bank calculations.
Forward-option split in Swiss franc

notional traded between November

2014 and March 2015

Chart 8

Chart 9

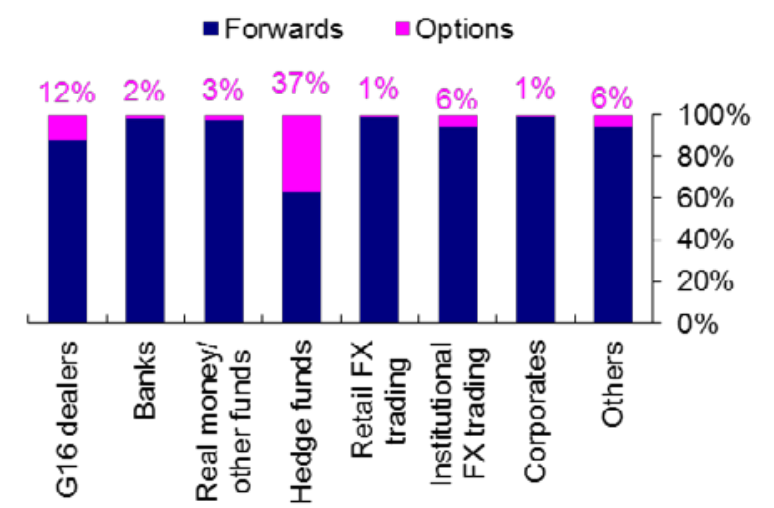

Source: DTCC and Bank calculations

\section{Market structure - a two tier market classification}

The granularity of the TR data allows us to describe in great detail the composition and structure of the FX OTC derivatives market - a first in the literature. Charts 8 and 9 showed that trading activity in the Swiss franc segment of the market is dominated by G16 dealers, which is consistent with the commonly-held view that a small number of big counterparties dominates OTC markets.

We dig into this result by reporting the shares of traded notional by dealer-client type in Chart 10 . More than $90 \%$ of trading involves a dealer as counterparty, i.e. only $2 \%$ of the trades did not involve any of the G16 dealers. The interdealer market accounts for a little over $49 \%$ of the total notional traded. The findings suggest that the $\mathrm{CHF}$ derivatives market is representative of a typical ${ }^{18}$ two-tier dealer-centric OTC market consisting of a top tier of inter-dealer trading and a second tier for end users to trade with the dealers.

We next look at the network of exposures using the two-tier dealer-to-client approach. Chart 11 presents the network diagram of the EURCHF forward market. ${ }^{19}$ In this Chart, node sizes are proportional to the number of links a counterparty has, while arrow thickness reflects the aggregated notional outstanding amount between two market participants. Dealers are depicted in red and clients as blue nodes. The first observation is the pronounced core-periphery structure. G16 dealers are central to the network, forming a densely connected backbone of the core. Dealer banks are surrounded by 'clouds of clients', typically small- and medium-sized banks, real money investors and corporates. There are also some centrally located clients (but not as big and as connected as dealers) in the middle which are served by several dealers. Gross exposures tend to be larger for dealers, while higher net exposures are

\footnotetext{
18 This emerging FX derivative structure is similar to that of other OTC markets. For example, Benos, Payne and Vasios (2016) and Benos, Wetherilt and Zikes (2013) report that the share of interdealer activity in OTC interest rate swap (IRS) and credit default swap (CDS) markets is about $55 \%$ and $60 \%$, respectively. One difference is the share of client-to-client trading in our data. The $3 \%$ that we observe is slightly smaller than that of the IRS market (about 6-12\%), but bigger than that of the CDS market (about 1\%).

19 We focus on the forwards market, because the smaller and less dynamic option market makes it less suited for a network description.
} 
more profound in the dealer-to-client segment. One exception is a particularly large gross exposure between a dealer and a large client (a hedge fund), the big pair of arrows in the bottom left part of the network. More generally, the analysis of the network of exposures can be a useful tool for identifying financial vulnerabilities and the build-up of systemic risk (see Joseph (2014)).

Notional traded between November 2014 and March 2015 in Swiss franc forwards and options by dealer-client type

- Dealer-to-Dealer = Dealer-to-Client $=$ Client-to-Client

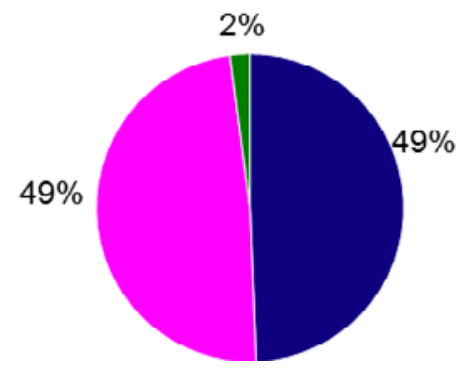

Source: DTCC and Bank calculations.

Visualisation of the traditional two-tier structure of the EURCHF forwards market on 14 January 2015

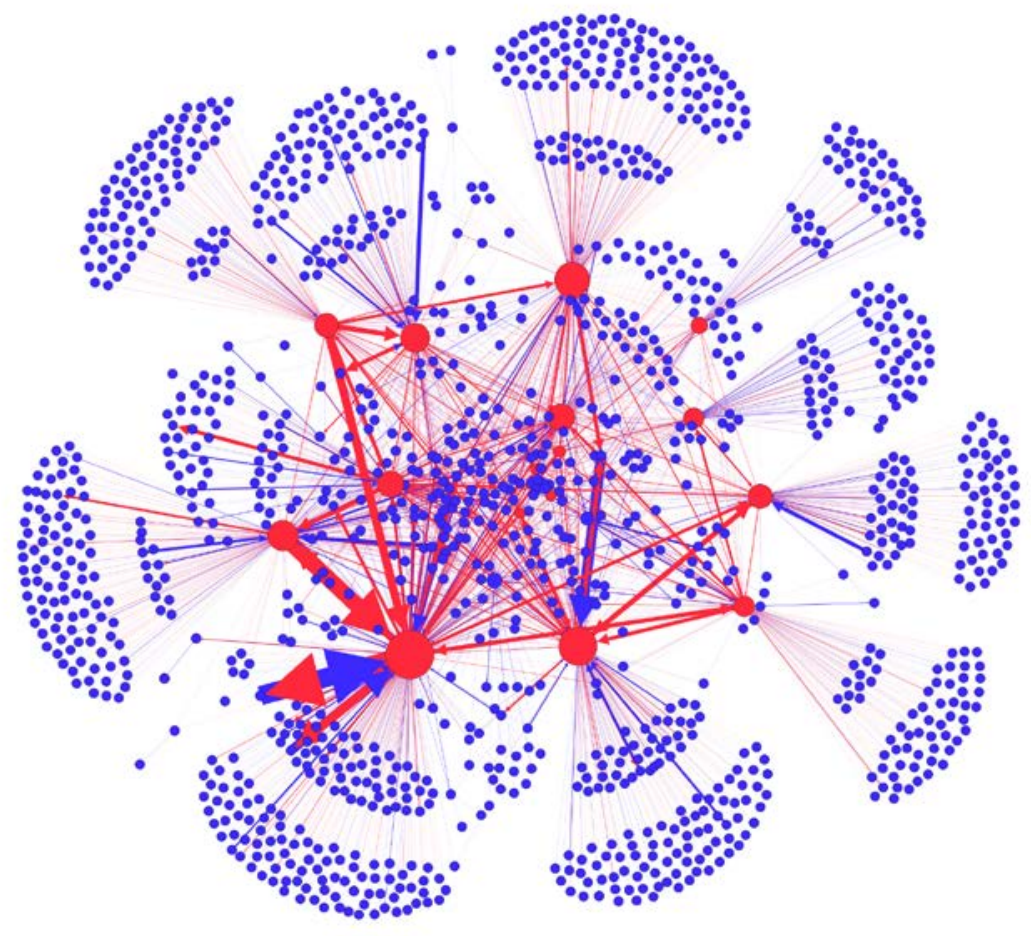

Red $=$ G16 dealers, blue $=$ clients

Source: DTCC and Bank calculations. 


\section{A network topology approach - a three tier market classification}

One of the limitations of the traditional two-tier market classification is that it does not distinguish between the different types of clients (the non-dealers). However, as Chart 11 demonstrated, clients in the middle of the network diagram are more connected and more active than the clouds of clients in the periphery. In other words, the client segment can be very heterogeneous.

One way to better capture this property of the network of exposures is by using techniques from network science (see Appendix and Barabási (2016)). Using the network topology, that is the shape of the network, we can split the EURCHF forwards market into three tiers: the inner core, the outer core and the periphery. More importantly, this approach only requires information about the properties of each node, such as the number of connections. Hence, we do not need to make any arbitrary assumption about who is a dealer or a client.

Charts 12 and 13 present the three-tier network classification and the breakdown of each tier by counterparty type, respectively. The node sizes are proportional to the Swiss franc gross position of individual counterparties (logarithmic scale). We can see that constituents of the three-tier structure are as follows. The inner-core, shown in red, consists of dealer banks which exhibit the largest number of connections to other counterparties. The outer core, shown in blue, largely contains banks, corporates and hedge funds. The remaining nodes, shown in green, represent the periphery, largely consisting of smaller banks, real money investors and other counterparties. ${ }^{20}$

The three-tier classification is stable during the whole observation period, i.e. there are no major changes in composition of the layers, although individual counterparties may occasionally move between the outer core and the periphery or leave the periphery (i.e. the market as a whole). The core nodes persistently hold more than $90 \%$ of notional position between them, while only constituting about $40 \%$ of counterparties. The three-tier classification may be helpful for assessing which firms are particularly important to the functioning of a market, or to identify potentially risky firms and constellations among them.

\footnotetext{
20 The "other" counterparties could not be identified due to missing data and the lack of external data sources for cross reference, i.e. they should fit into one of the specific categories and "other" is not a true separate category. These counterparties represent less than $5 \%$ of gross positions.
} 
Visualisation of the three-tier structure of the EURCHF forwards market on 14 January 2015

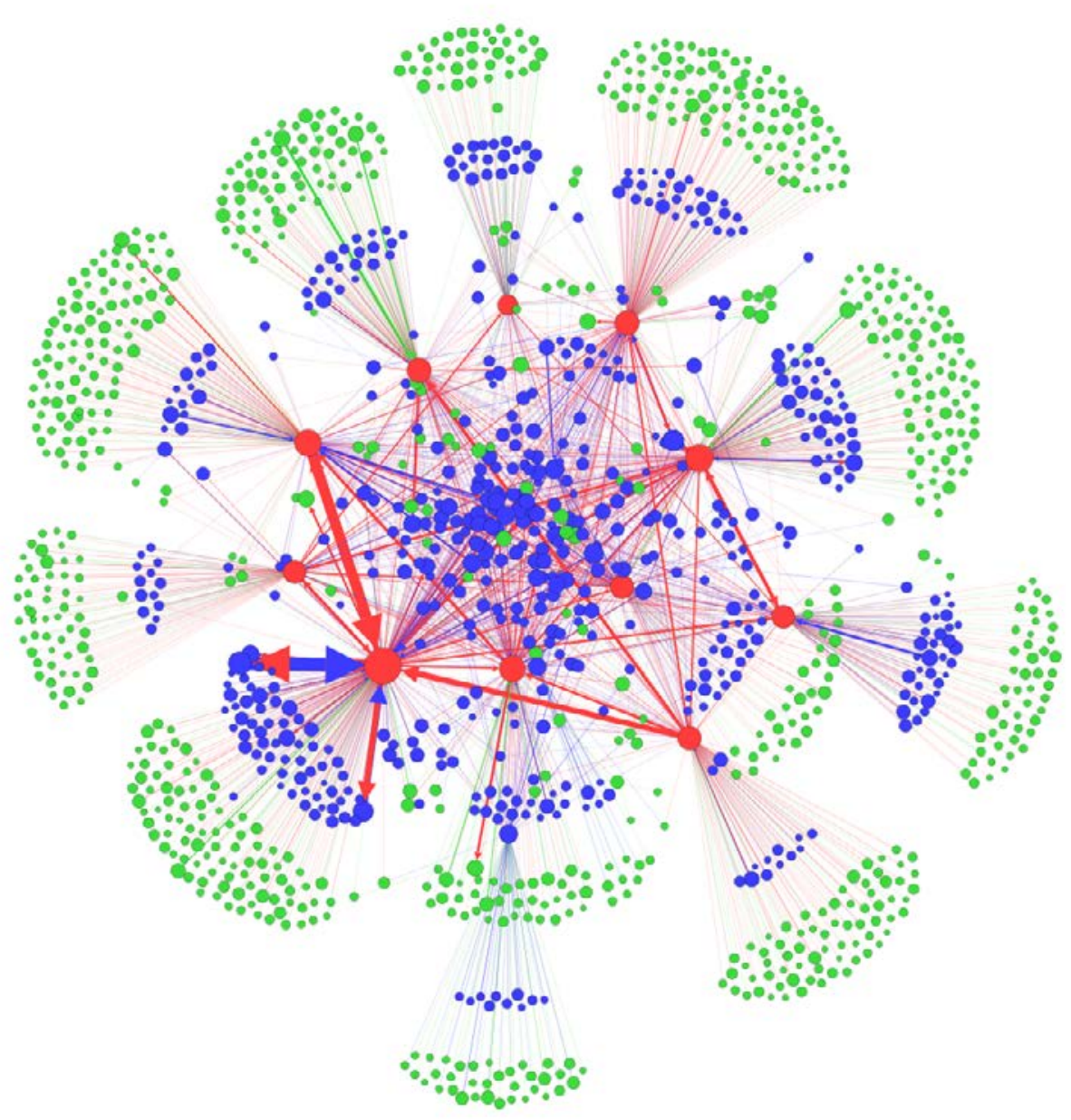

Red $=$ inner core, Blue $=$ outer core, green = periphery

Source: DTCC and Bank calculations.

Composition of different layers on 14 January 2015 by counterparty type

Chart 13
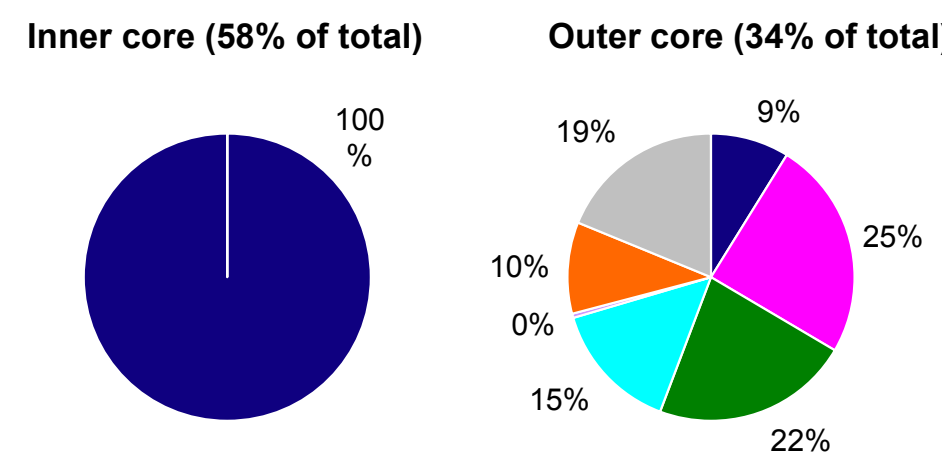

Periphery ( $8 \%$ of total)

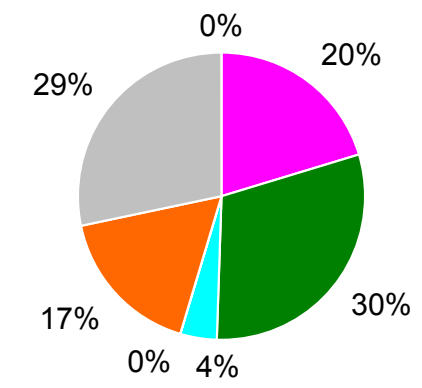

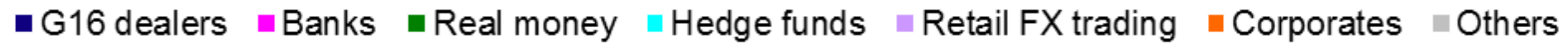
Source: DTCC and Bank calculations 


\section{Market impacts from de-pegging the Swiss franc}

The surprise change in SNB policy is one of the key events that took place in the FX market in 2015. One of the key features that distinguishes the event is the fact it was almost completely unexpected by market participants as far as we can determine from the data. In this section we describe the events on 15 January, first, by reconstructing the intraday activity trade-by-trade. We then examine the immediate impact of the SNB announcement, as well as its longer-term effects on market activity, liquidity, and structure of the network of counterparty positions.

\section{The SNB announcement and its impact on the Spot FX market}

At 9.30am UK time the SNB surprised the markets by announcing it was discontinuing the 1.20 EURCHF floor that had been in place since September 2011. ${ }^{21}$ The SNB also announced it was lowering the interest rate on sight deposit account balances that exceed a given exemption threshold by 50 basis points to $-0.75 \%$ and moving the target range for the three-month CHF Libor further into negative territory (from between $-0.75 \%$ and $0.25 \%$ previously to between $-1.25 \%$ and $-0.25 \%$ ).

\section{Spot EURCHF trades executed on EBS platform on 15 January 2015}

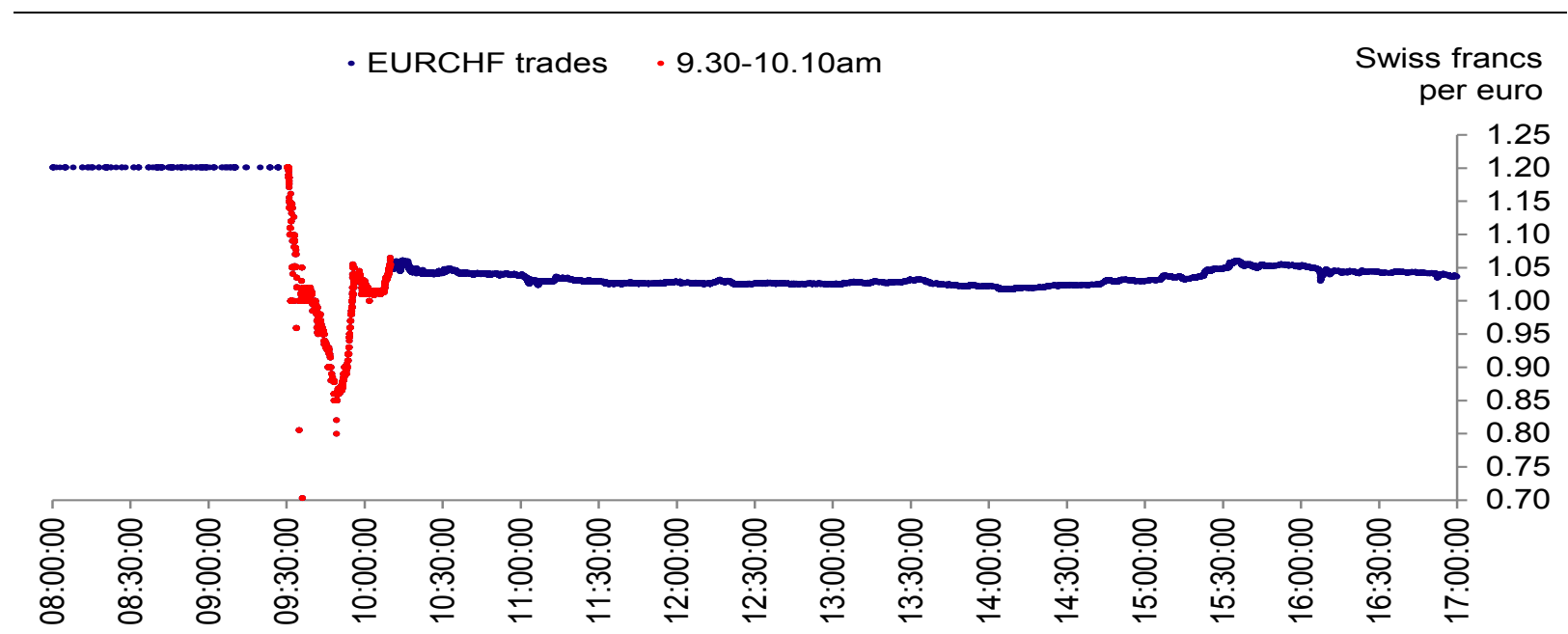

Note: We have removed one EBS trade at 9.32 am with a price of just 0.0015 . EBS confirmed on the day that the highest value of the Swiss franc traded on the day was 0.85 franc per euro.

Source: EBS and Bank calculations.

The speed and scale of the subsequent currency moves was unprecedented, as shown in Chart 14, which uses spot FX data on individual transactions from EBS. Shortly before the announcement, EURCHF was trading slightly above 1.20. The exchange rate dropped below the 1.20 floor for the first time 47 seconds after the announcement. Two minutes after the announcement, the Swiss franc had appreciated by $11 \%$ against the euro. After seven minutes, it was $19 \%$ higher. It continued to appreciate to reach a peak of 0.85 francs per euro at $9.49 \mathrm{am}$, an unprecedented $41 \%$ appreciation. It subsequently eased back, falling nearly as fast as in the initial upward move. By around $10.10 \mathrm{am}, 38$ minutes after the announcement, the franc was 'only' up 15\% from its pre-announcement level at around 1.05, where it remained for most of the day. The franc ended the day $14 \%$ higher against the euro,

\footnotetext{
21 You can find the SNB press release on discontinuing the 1.20 EURCHF minimum exchange rate here:
} https://www.snb.ch/en/mmr/reference/pre 20150115/source/pre 20150115.en.pdf 
and $12 \%$ higher against the US dollar, representing $23-$ and 15 -standard-deviation moves, respectively, compared to daily changes in the last eight years, although it is important to note that the standard deviation would have been artificially lower during the period the EURCHF floor was in place.

\section{Reconstructing the SNB event trade-by-trade using EMIR TR data}

We next use the TR data and reconstruct the trading book on the 15 January 2015. We start with traded prices and notional for the five-day EURCHF forward market. This segment accounted for nearly half (49\%) of all EURCHF forwards traded on that day, hence it is a good representation of the whole market. Chart 15 shows all executed trades on the event day, each trade represented by a bubble whose size is proportional to the notional. Trades executed in the interval between 9.30 am and $10.10 \mathrm{am}$, when prices crashed before recovering to the new equilibrium price, are shaded in red.

The pattern is similar to what we observe in the spot market in Chart 14, yet with much higher price dispersion. The price of five-day forwards fell sharply following the SNB announcement. We observe three trades executed at forward rates below 0.80 , one at $9.33 \mathrm{am}$ and two at $9.34 \mathrm{am}$. The lowest price was 0.65 , but the notional traded was extremely small (for this market) at less than USD 1,000. Apart from these three small trades, the price troughed at the same exchange rate as in the spot market (0.85), at the same time (just before $9.50 \mathrm{am}$ ). We do observe a small number of trades executed within an hour after the announcement at prices which seem substantially higher than the prevailing price, around 1.15. These might be genuine trades or there might be some issues with the reported execution timestamp. Since these trades have relatively small notional values they do not have a significant impact on the analysis.

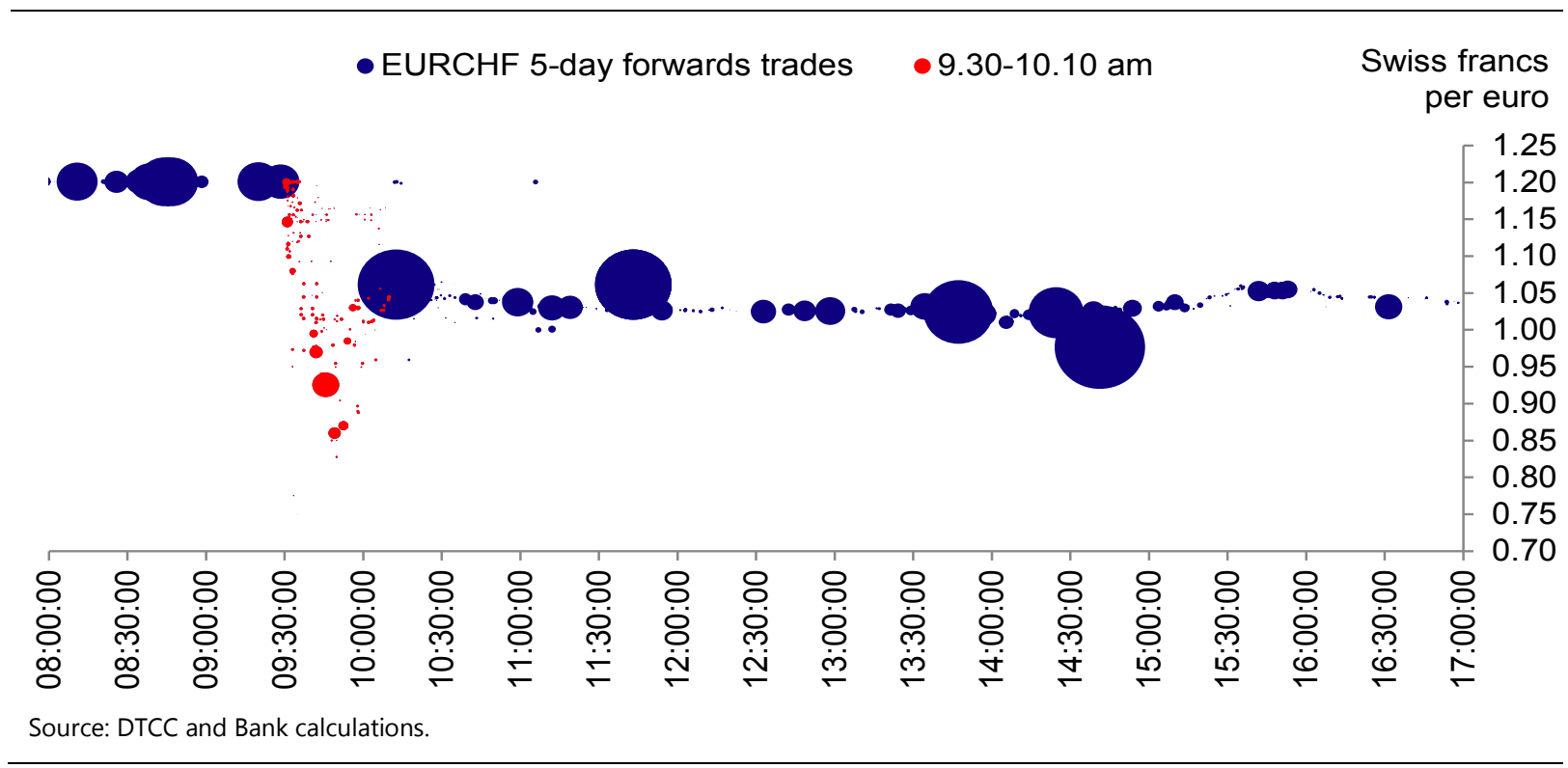

The SNB announcement appears to have taken markets by surprise and made investors to rush into the market to adjust their portfolios, take new hedges or engage in speculative activity. Hence, the sharp price decline to what seemed to be the new EURCHF fair value was expected to some extent: prices adjusted through the trading process. It is the V-shaped price movement, which is highlighted in red, which makes 
Chart 15 interesting. If markets were efficient, as economic theory suggests, we should not observe such an exchange rate fluctuation and divergence from fundamentals. One explanation might be the limited provision of liquidity between 9:30 am and 10:10 am. In what follows we examine if this is the case by looking at the different phases of the intraday price movement in conjunction with the trading behaviour of different types of counterparties. We describe each of these in turn, focusing on the building-up of inventories, i.e. the cumulative net positions, and the structure of the trading network. We are particularly interested to see how dealers and the inner-core of the trading network, who are believed to provide liquidity in OTC markets, responded to the SNB announcement. We decompose the events of 15 January into three parts:

- $\quad 9.30-9.50 \mathrm{am}$, when the Swiss franc was appreciating from 1.20 to a low of 0.85

- $\quad 9.50-10.10 \mathrm{am}$, when the franc was depreciating from 0.85 to around 1.05

- 10.10 am onwards, when the franc stabilised and activity in the market picked up.

\subsection{0-9.50 am: Swiss franc appreciation}

Chart 16 shows that the number of Swiss franc forwards trades surged in the minutes after the announcement. Between 9.30 and 9.35 am alone there were 268 EURCHF forwards trades, which was nearly 60 times the average trading for a given five-minute interval between $9.00 \mathrm{am}$ and $3.00 \mathrm{pm}$ before the change in SNB policy in our dataset. The number of trades remained above average for the rest of the day. Despite this increase in the number of trades executed between 9.30 and 9:50 am, the total notional traded remained low. This means that the average size of trades executed in this time period was small, which can be seen in the small size of the red bubbles in Chart 15

We next look at the behaviour of different counterparties immediately after the SNB announcement. Charts 16 and 17 present the cumulative net positions, i.e. the difference between aggregate long and short positions, of dealers and the different tiers, respectively. Chart 16 also reports the total notional traded in the dealer-toclient market in 5-minute intervals. A first observation is that the dealer-to-client market was very thin in terms of notional traded in the 20 minutes after the event, while dealers' net position was close to zero. A similar picture emerges when we use the 3-tier classification instead, where we see that the inner-core net positions were small too. The observed limited provision of liquidity is surprising given that many market participants wanted to buy the Swiss franc in this time period to capitalise on profits from the expected currency appreciation (i.e, buy low - sell high strategy). On the contrary, we observe that the key liquidity providers were unwilling to build-up any potentially loss-making positions by selling the currency to the interested parties. In fact, immediately after the SNB announcement dealers were net buyers of the Swiss franc. This suggests they were initially consuming liquidity instead of providing it, potentially exacerbating the sharp rise in the franc. 
EURCHF forwards cumulative dealer position and dealer-to-client notional traded.

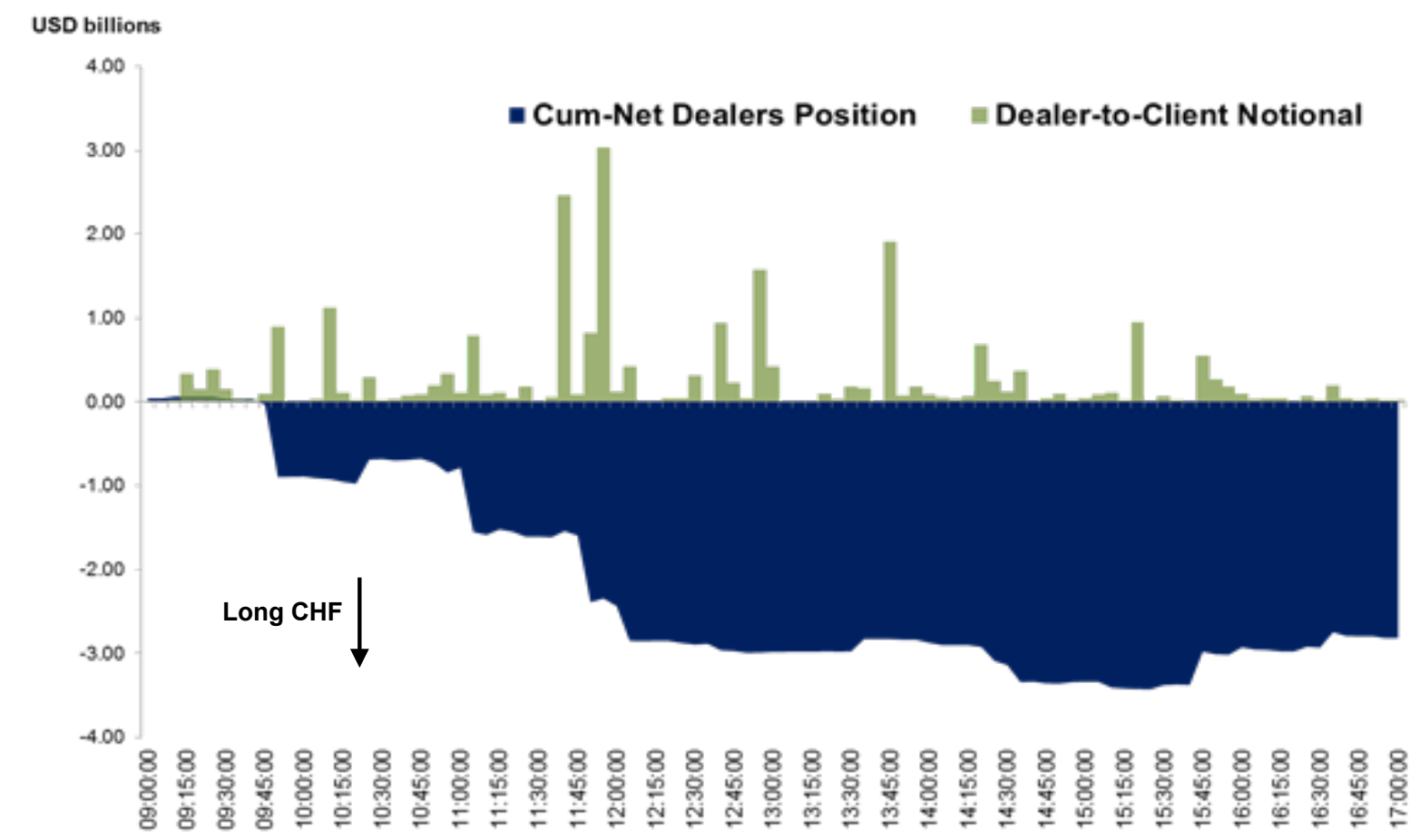

Source: DTCC and Bank calculations.

EURCHF forwards cumulative position by tier.

Chart 17

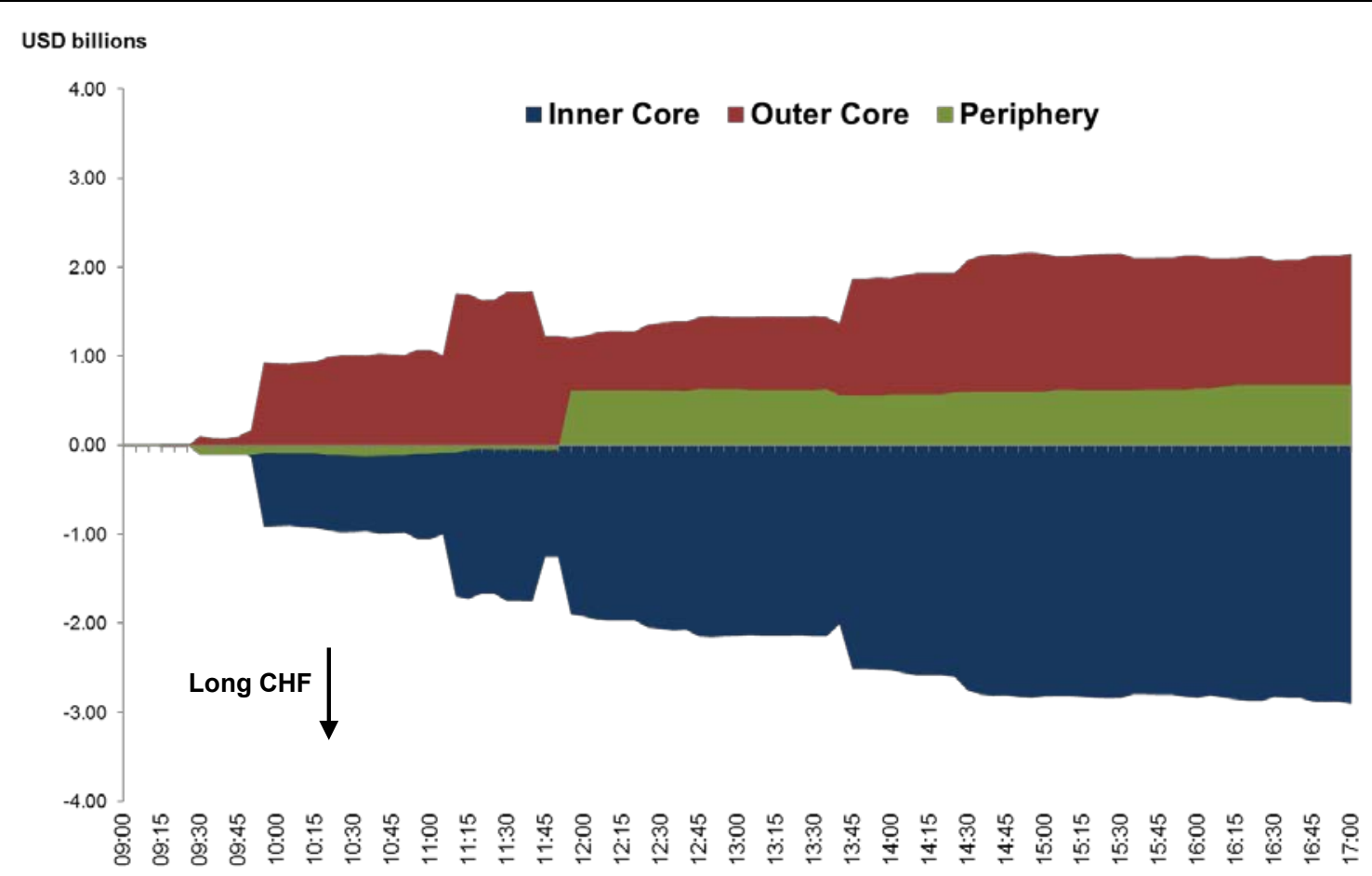

Source: DTCC and Bank calculations 
In Chart 18, we zoom in on trading behaviour using more granular data. Here each bubble represents a counterparty that was present in the market, with the size of the bubble proportional to the gross notional traded by the given counterparty in this time period. ${ }^{22}$ Arrows pointing away from a counterparty mean this counterparty was selling the Swiss franc, while the width of the arrows represent the size of the trade. The arrows are also coloured according to the weighted average price at which trades were executed between given counterparties. Blue arrows represent trades with forward exchange rates close to 1.20, while red arrows are trades executed below parity. So for instance a blue arrow pointing away from a counterparty means the counterparty had sold the Swiss franc at a cheap price (a high EURCHF exchange rate), presumably leading to a loss. Similarly, a red arrow pointing to a counterparty means the counterparty in question bought the Swiss franc at an expensive price (a low EURCHF exchange rate), also seemingly at a loss.

The network diagram shows that eleven of the G16 dealers were present in the market during the first twenty minutes, but with limited dealer-to-client trading. Only three dealers appeared to provide liquidity to non-dealers (upper centre and bottom left), whereas the rest were active only in the inter-dealer market. The clients who managed to find liquidity were mainly banks, hedge funds and few corporates. A few dealers started providing liquidity after 9.45 am when the exchange rate fell below parity against the euro, in the sense that, they were buying Swiss franc at unfavourable prices, even if this activity was potentially loss-making.

Trading activity by counterparty type in EURCHF forwards market between 9.30 am and 9.50 am (Swiss franc appreciation)

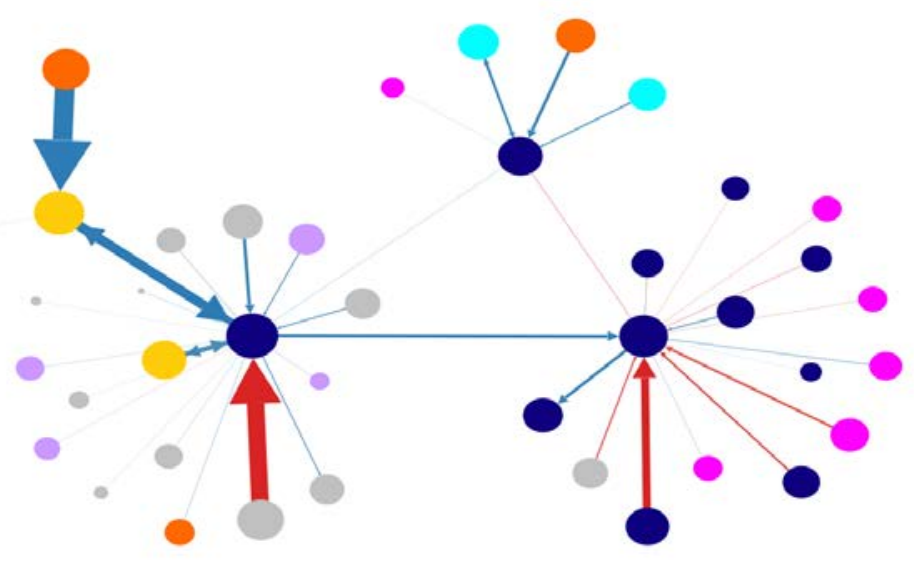

- G16 dealers $=$ Retail FX trading
- Banks $\quad$ - Real money

= Institutional FX trading $=$ Corporates
= Hedge funds

- Others

Source: DTCC and Bank calculations.

${ }^{22}$ A logarithmic scale has been used for the size of the nodes to allow all the market participants to be displayed clearly. Some of the larger nodes would have been much larger if a linear scale had been used. 


\subsection{0-10.10 am: Swiss franc depreciation}

In the subsequent 20-minute period between 9.50 am and 10.10 am (see Chart 19) there was more dealer-to-client activity with dealers building-up larger and potentially loss making positions. This can be seen in the increasingly net long Swiss franc positions of dealers and the inner-core in Chart 17. The network diagram shows it was mainly the outer-core that was consuming liquidity, while the periphery remained relatively inactive. When looking at the trading behaviour of individual counterparties we observe there were five dealers providing liquidity to non-dealers, up from three in the previous 20-minute period. These dealers were at the core of clouds of different clients and were actively buying and selling Swiss franc. Clients consisted of mainly banks, real money investors and corporates. The seemingly stronger engagement of dealers in the provision of liquidity coincided with the price reversal to the new equilibrium level at about 1.05 Swiss franc per euro.

Trading activity by counterparty type in EURCHF forwards market between 9.50 am and $10.10 \mathrm{am}$ (Swiss franc depreciation)
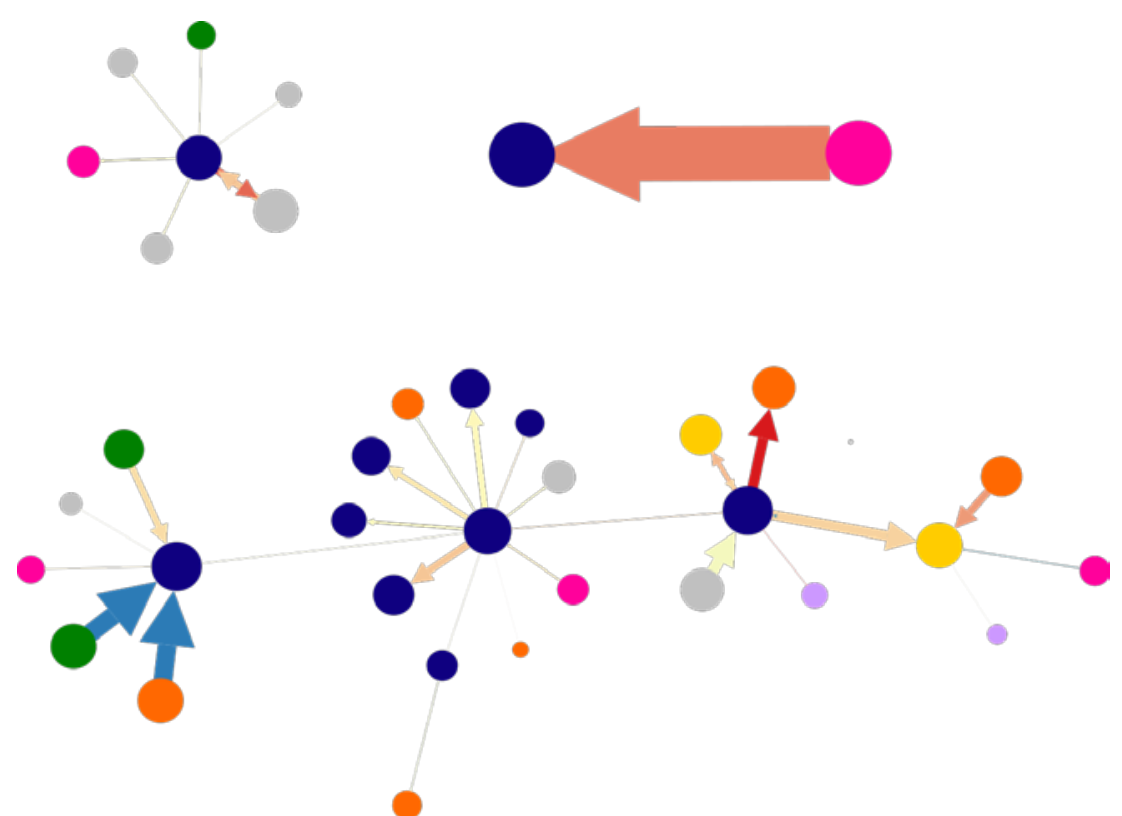

- G16 dealers

$=$ Retail FX trading $\begin{array}{ll}=\text { Banks } & \square \text { Real money } \\ =\text { Institutional FX trading } & =\text { Corporates }\end{array}$
- Hedge funds

= Others

Source: DTCC and Bank calculations.

\subsection{0 am onwards: Swiss franc stabilises}

Most of the other counterparties, such as hedge funds, real money investors and corporates re-entered the market only after the price of the Swiss franc stabilised at around $10.10 \mathrm{am}$. For example, trading volumes between the inner- and outer-core increased dramatically after $10.10 \mathrm{am}$, with the former taking long Swiss franc positions and the latter short. Around midday the periphery also became more active and started building up short positions. Around the same time we observe that the traded notional in the dealer-to-client market peaked too. Dealers' net long position continued to increase throughout the day as dealers bought the Swiss franc from their clients. 
Overall, the evidence suggests that in the first 20 minutes after the event there was limited provision of liquidity as (i) it was difficult to execute any large trade as demonstrated by the small average trade size, (ii) there was limited dealer-to-client trading, and (iii) dealers seemed to be unwilling to build up potentially loss-making inventories. This impairment of liquidity might explain to some extent the sharp appreciation of the Swiss franc (i.e. overshooting). When dealers started engaging more in the dealer-to-client market, the buying pressures to the Swiss franc eased, prices reversed and gradually stabilised.

The $V$-shaped price movement between 9.30 am and $10.10 \mathrm{am}$, together with the evidence on the prevailing market liquidity conditions, fits well with the literature that examines the limits to arbitrage (see for example Shleifer and Vishny, 1997). The basic idea of limits to arbitrage is that arbitrage becomes ineffective in extreme circumstances, for example because of the lack of market liquidity, which causes prices to diverge far from fundamental values. In the case of the Swiss franc depegging, if more liquidity had been available, arbitrageurs might not have allowed the Swiss franc to appreciate above the new equilibrium price. In other words, we should have seen the exchange rate quickly move to the seemingly new equilibrium price of around 1.05 .

\section{Long-term impact on liquidity, volatility and collateralisation}

Analysis of both the network structure and trading activity in Section 4.2 implies limited liquidity provision on the day of the event. Here we look into the impact of the SNB action on market liquidity by comparing liquidity levels before and after the event. The main limitations we face for measuring liquidity is that we cannot use one common method of doing this by using bid and ask quotes as we are relying on trade data. As a result, we rely on metrics that require only executed prices to proxy effective spreads and hence liquidity. For all of these measures, a higher value indicates lower liquidity.

The first is the Roll (1984) effective spread measure, which is based on the serial covariance of changes in prices. The measure is defined as:

$$
\operatorname{Roll}_{\mathrm{i}, \mathrm{t}}=10,000 * 2 * \sqrt{-\operatorname{cov}\left(\mathrm{R}_{\mathrm{i}, \mathrm{s}}, \mathrm{R}_{\mathrm{i}, \mathrm{s}-1}\right)},
$$

where $\mathrm{R}_{\mathrm{i}, \mathrm{s}}$ is the intraday return between transaction $\mathrm{s}-1$ and $\mathrm{s}$, for contract $\mathrm{i}$ on day t. This is shown in Chart 20.

The second is based on the price dispersion measure of Jankowitsch, Nashikkar, and Subrahmanyam (2011), which we define as the average of the relative differences between individual execution prices and the average execution price on day t. More formally,

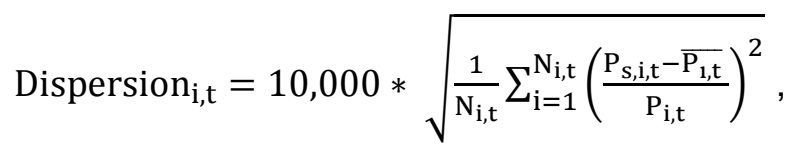

where $\mathrm{N}_{\mathrm{t}}$ is the total number of trades executed for contract $\mathrm{i}$ on day $\mathrm{t}, \mathrm{P}_{\mathrm{s}, \mathrm{i}, \mathrm{t}}$ is the execution price of transaction $s_{\text {, and }} \overline{\mathrm{P}}_{\mathrm{t}}$ is the average execution price on contract $i$ and day $t$. This is based on the premise that traded prices may deviate from the expected value of an asset because of inventory risk for dealers and search cost for investors. 
Both metrics have been derived from market microstructure models and are commonly used in the context of OTC derivatives markets as proxies of transaction costs (see for example, Goyenko et al. (2009), Friewald, Jankowitsch and Subrahmanyam (2014), and Benos, Payne and Vasios (2016) among others).

Other than the liquidity measure we have also estimated daily variance from intraday data. To do this we use the sum of the squares of the high-frequency returns within a given day, which is the standard definition of the realised variance measure of Barndorff-Nielsen and Shephard (2002). Finally, we present the average trade size before and after the SNB announcement, which can also been seen as a proxy for liquidity (market depth).

For collateralisation, on the day of the event we observe an increase in the proportion of trades that are fully collateralised between market participants This might reflect an increase in counterparty risk following the change in the SNB policy, another potential driver of the increase in transaction costs.

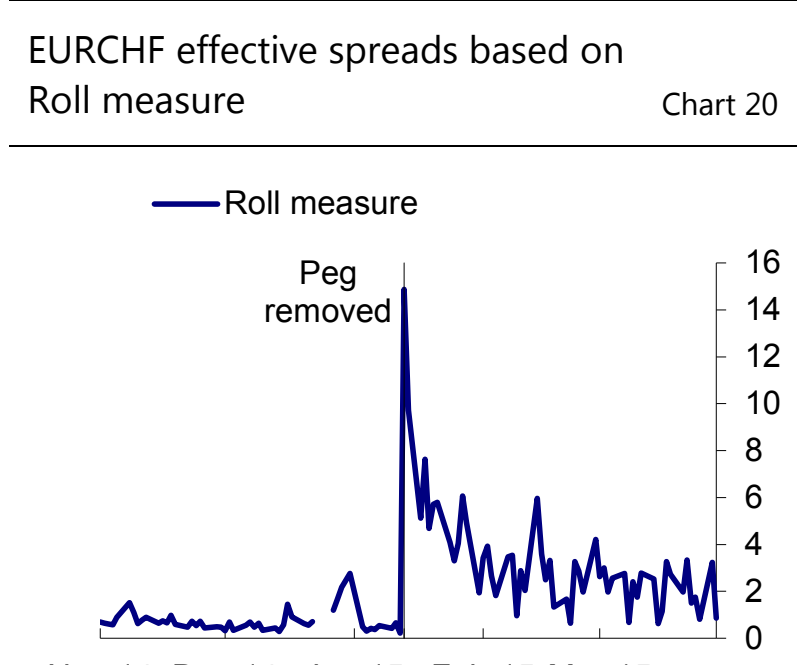

Nov-14 Dec-14 Jan-15 Feb-15 Mar-15
EURCHF price dispersion and

realised variance

Chart 21

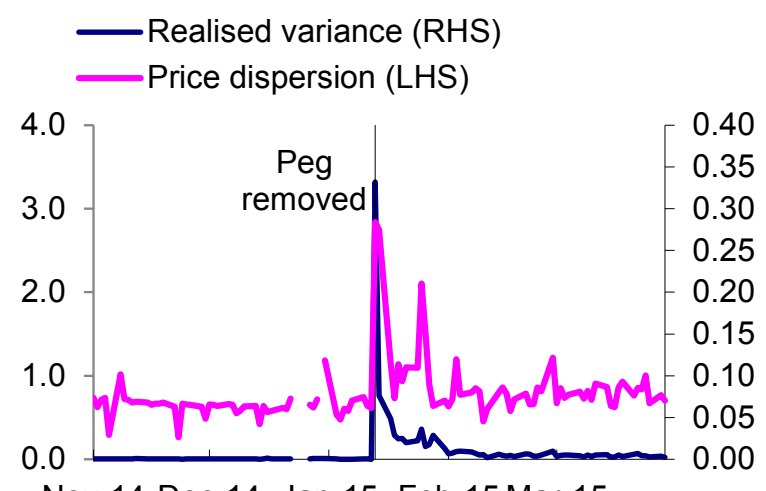

Nov-14 Dec-14 Jan-15 Feb-15 Mar-15

Source: DTCC and Bank calculations.

Notional traded of uncollateralised

Average trade size before, on and after 15 January

Chart 22

Chart 23

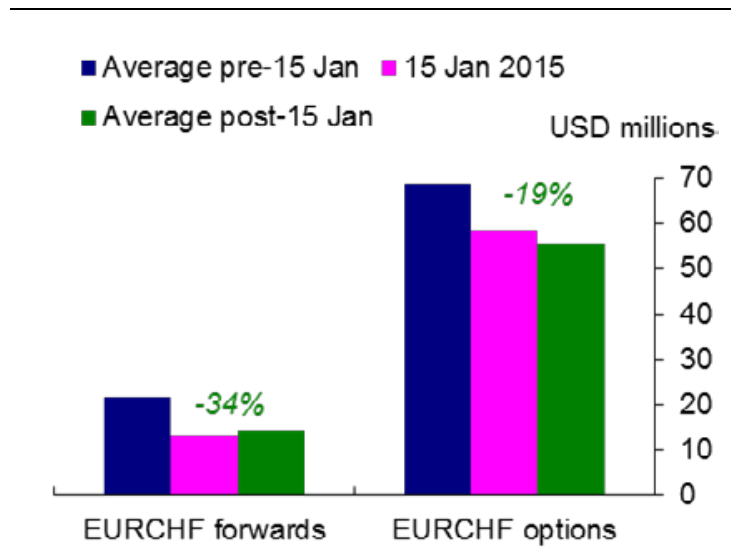

Source: DTCC and Bank calculations.

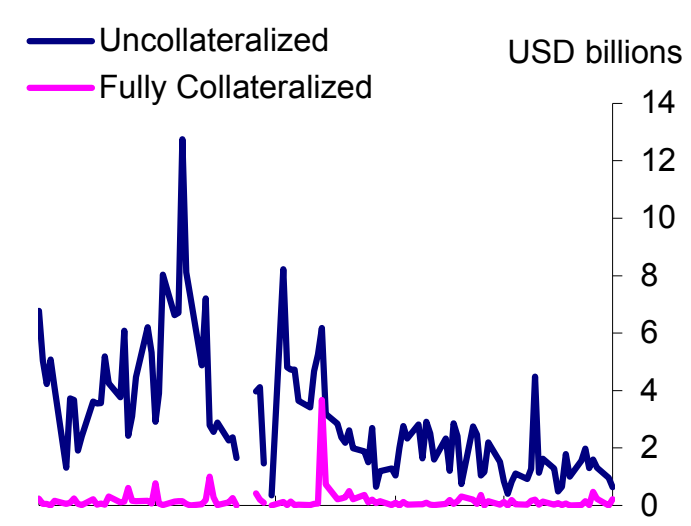

Nov-14 Dec-14 Jan-15 Feb-15 Mar-15

Source: DTCC and Bank calculations. 
Charts 20 and 21, present the liquidity metrics for the EURCHF forward market, which includes all forwards contracts with maturities up to five days ${ }^{23}$. The Chart shows that the two liquidity measures provide essentially the same qualitative picture. Market illiquidity rose sharply on 15 January and remained at a high level for the remainder of our sample period. This long-term impairment of market liquidity in the new exchange rate regime is more evident in the case of the Roll effective spread measure. Overall, trading in the Swiss franc OTC derivatives market appears to have become more costly after the change in policy. This may be because the trading costs were artificially depressed while the floor was in place.

Realised variance also rose sharply on the event day and remained at an elevated level. The pattern of volatility might explain to some extent the impairment of liquidity in the months following the SNB announcement. The reason is that the increased volatility is expected to have increased (i) inventory costs for dealers, since market risk increased too, and (ii) information asymmetry, both of which are considered to be the two main determinants of dealer illiquidity. ${ }^{24}$ Therefore, if the removal of the floor made it more costly for dealers to provide liquidity, they might have passed these costs to other market participants by charging a wider bid ask spread, thus hurting liquidity.

A similar picture arises when we look at the average trade size variable. Chart 22 shows that the drop in average trade size, observed on 15 January persisted for the remainder of our sample period. Post announcement we observe the average trade sizes for EURCHF forwards and options were 34\% lower and 19\% lower, respectively (although the drop in EURCHF options trade size is not statistically significant). The smaller trade size might reflect dealers' inability (or unwillingness) to accommodate trading of large positons.

\section{Impact on the trading network and market fragmentation}

We next look at whether the change in SNB policy had an impact on the structure of the Swiss franc trading network, as this could provide a micro-founded explanation for the market phenomena observed in the previous sections. We observe that a large number of new counterparties entered the Swiss franc market on 15 January. Many new entrants were small counterparties which were not classified. ${ }^{25}$

We assess the impact on the trading network by looking at the trading backbone network of the market, which we define as the network formed by reciprocal-only daily trading links of comparable contracts in the five-day forward market. The basic idea of this approach is to gauge the event's impact on the most active parts of the market. For this, we measure the number of connected components in the trading backbone on each day. A connected component is a part of a network within which

23 When calculating the liquidity metrics and the realised variance, we remove all trades executed before 10.10 am on 15 January. We do so to control for the rapid Swiss franc appreciation immediately after the event.

24 For instance, seminal papers by Glosten and Milgrom (1985) and Kyle (1985) have shown that asymmetric information is positively related to illiquidity. This is because market makers or dealers tend to ask an additional compensation to offset their potential losses on trades with better informed investors. This is known as adverse selection. Stoll (1978) was the first to show that inventory risk plays an important role for market liquidity too. The basic idea is that as dealers accumulate positions they are exposed to losses from adverse price movements, because not all of these positions can be unwound immediately. Dealers tend to pass these losses to other market participants by charging a wider bid ask spread.

25 This is both because of lack of LEIs and the fact these counterparties' exposure fell below the threshold we used for classifying firms actively (there being no definitive source of counterparty sector information currently). 
every node can be reached from every other node across at least one path going along the network's links. For example, a market where all counterparties are connected to each other consists of one component. If we split this market into two parts that are not connected to each other, then we will increase the number of components to two. Intuitively, a large number of components will indicate a high degree of market fragmentation.

We apply this approach to the EURCHF forward market in Chart $11 / 12 .{ }^{26}$ The results are shown in Chart 24. The blue line reports the number of connected components (of at least three counterparties). A value of one indicates that everyone was linked in a single network, while higher values mean the trading network was made up of two or more separate parts. We observe that the market appears to have become more fragmented after the removal of the EURCHF floor, with the number of unconnected sub-components increasing to about 4.5 from 3.5. ${ }^{27}$ This might have been driven by dealers' unwillingness to facilitate trading among different parts of the network, as a result of the increased transaction costs in the same period (see Section 4.3).

We test this assertion by looking at the number of interdealer links before and after the SNB event. This is defined as the number of inter-dealer links as a proportion of all links and is presented in Chart 25. We observe a decline in the average number of interdealer links, which is however, less pronounced than the average increase of the number of connected sub-components. Note, however, that the variation of the number of long-range connections in a network, which are given by inter-dealer links in our case, can have far-reaching implications for its aggregated properties (see Albert and Barabási (2001)). For instance, liquidity and price dispersion are expected to be affected by the amount of inter-dealer activity.

We look at the impact of the SNB event on market fragmentation and interdealer links more formally in Table 1 , where both variables are regressed on a number of date dummies. The post SNB event dummy equals 1 after the event and 0 otherwise, and it captures the longer-term effects of the event. The Wednesday dummy equals 1 on 14 Jan 2015 and 0 otherwise, while the Thursday and Friday dummies are defined in the same fashion. The results in Table 1 show that the $5 \mathrm{~d}$ EURCHF forward market became more fragmented in the weeks following the SNB event. In the same period the number of interdealer links decreased. All these effects are strongly statistically significant.

As an illustration of the higher market fragmentation we compare the backbone activity on two days: the event day and 21 January (one week after the event), which are depicted on the left- (LHS) and right-hand-side (RHS) of Chart 26, respectively. Chart 26 shows that the trading network on 15 January was very dense. Most clients were connected to their corresponding dealers in star-shaped sub-structures (rather than connecting parts of the network), and all dealers were connected to each other through the interdealer market. As a result there was just one connected component. In contrast, the number of connected components increased to two on 21 January. This is true for most days after the removal of the floor.

\footnotetext{
26 The EURCHF option market is too illiquid to construct similar measures.

${ }^{27}$ It can be shown that the increase in the number of sub-components after the event is statistically significant
} 
Number of connected components of at least three counterparties in the Swiss franc market
Dealer-to-dealer links as fraction of all links

Chart 24

Chart 25
Connected components Number of

- - Average pre-SNB

- - - Average post-SNB

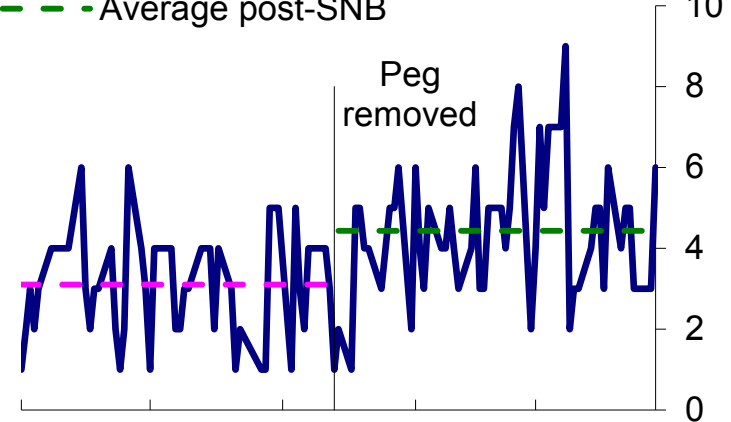

Nov-14 Dec-14 Jan-15 Feb-15 Mar-15 components

10

6
Fraction of dealer-to-dealer links

- Average pre-SNB

- - Average post-SNB

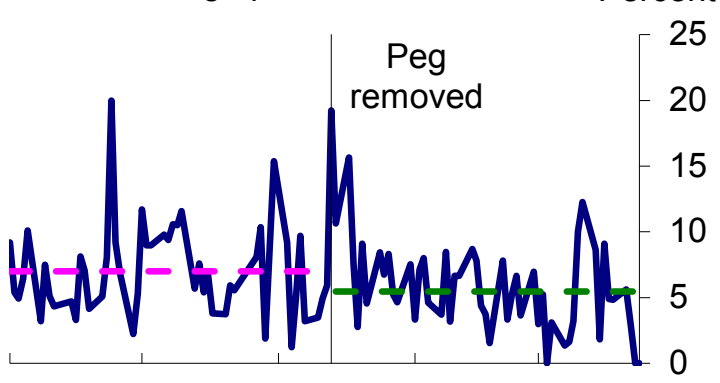

Nov-14 Dec-14 Jan-15 Feb-15 Mar-15

Schematic description of the fragmentation of the EURCHF forwards market cores (LHS: 15 January, RHS: 21 January)

Chart 26
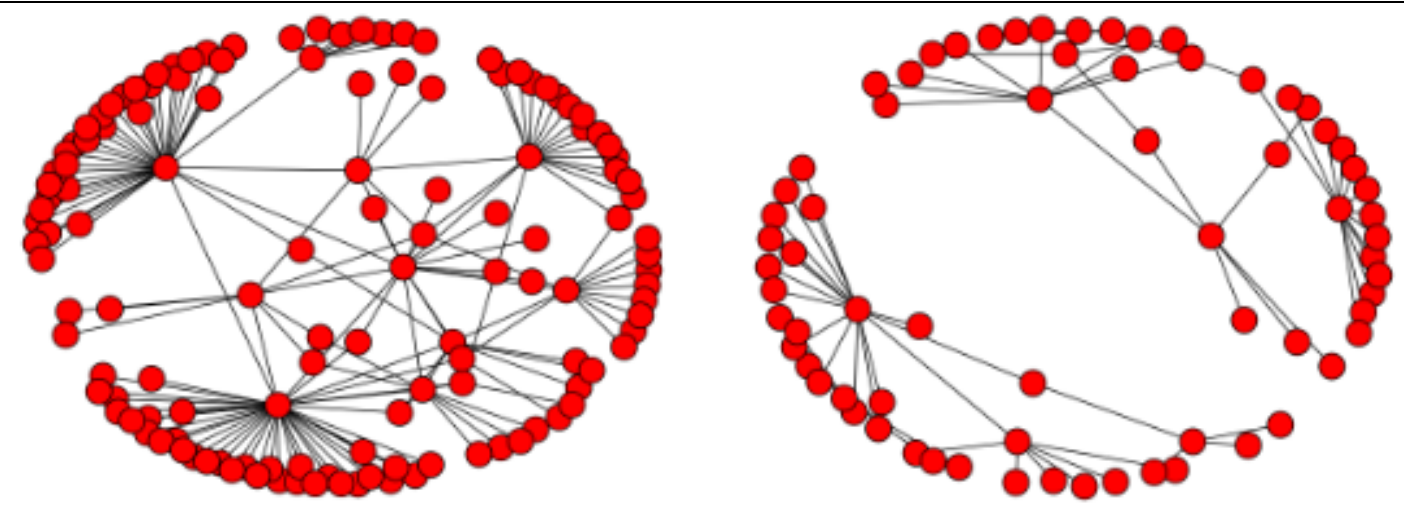
Regression analysis of the impact of the SNB event on the trading network of the $5 d$ EURCHF forward market. Robust t-statistics are shown in the square brackets. ${ }^{*}{ }^{* *}$ and ${ }^{* * *}$ denote significance at $10 \%, 5 \%$ and $1 \%$ levels respectively

Table 1

\begin{tabular}{lcc}
\hline & Fragmentation & \\
\hline Wednesday (14/01) & -0.102 & $-0.0107^{* *}$ \\
& {$[-0.531]$} & {$[-2.111]$} \\
Thursday (15/01) & $-2.102^{* * *}$ & $0.122^{* * *}$ \\
& {$[-10.93]$} & {$[24.00]$} \\
Friday (16/01) & $-1.102^{* * *}$ & $0.0362^{* * *}$ \\
& {$[-5.732]$} & {$[7.118]$} \\
Post SNB event (17/01-31/3) & $1.379^{* * *}$ & $-0.0164^{* *}$ \\
& {$[4.652]$} & {$[-2.421]$} \\
Constant & $3.102^{* * *}$ & $0.0702^{* * *}$ \\
& {$[16.13]$} & {$[13.78]$} \\
$\mathrm{R}^{2}$ & 0.216 & 0.188 \\
Adjusted-R2 & 0.185 & 0.155 \\
$\mathrm{~N}$ & 104 & 104 \\
\hline
\end{tabular}

\section{Conclusions}

In this study, we present the first in-depth and large-scale study of the FX derivatives market using trade repository (TR) data resulting from the EMIR reporting framework. TR data cover bilateral trading activity on a trade-by-trade basis and information on outstanding contracts, which can be used to gauge exposures in a detailed manner. Thus, they provided us with a great wealth of information about activity in the FX derivatives market. Using data from a single large $T R$, we investigated the properties of the EURCHF forward and option market and analysed the impact of SNB's decision to discontinue the floor of 1.20 Swiss francs per euro on the morning of 15 January 2015. Importantly, TR data allow us to understand the complex structure of OTC markets and analyse the provision of liquidity during adverse market conditions.

We observe a decline in market liquidity and increase in market volatility after the SNB's announcement, which also had lasting consequences for the market. The TR data gives us the ability to carry out an intraday analysis of the prevailing trading conditions on the event day. We find that there was very little activity immediately after the SNB announcement, particularly in the dealer-to-client segment of the market. This might reflect dealers' unwillingness (or inability) to provide liquidity, which potentially exacerbated the sharp rise and then decline in the franc in the first 40 minutes of the event. 


\section{References}

Albert R. and Barabási, A. L., 2002. "Statistical mechanics of complex networks" Rev. Mod. Phys 74, 47.

BIS, 2015. "OTC derivatives statistics at end-December 2015".

Barndorff-Nielsen, Ole E., and Shephard, M., 2002. "Estimating quadratic variation using realized variance." Journal of Applied Econometrics 17.5: 457-477.

Benos, E., Wetherilt, A., Zikes, F., 2013. The structure and dynamics of the UK credit default swap market. Bank of England Financial Stability paper No 25.

Benos, E., Payne, R., Vasios, M., 2016. "Centralized trading, transparency and interest rate swap market liquidity: evidence from the implementation of the Dodd-Frank act". Bank of England Working Paper No. 580.

ESRB, 2016, "Shedding light on dark markets: First insights from the new EU-wide OTC derivatives dataset".

Friewald, N., Jankowitsch, R., Subrahmanyam, M. G., 2012. "Illiquidity or credit deterioration: A study of liquidity in the US corporate bond market during financial crises". Journal of Financial Economics 105 (1), 18-36.

Glosten, L. R., and Milgrom P. R., 1985. "Bid, ask and transaction prices in a specialist market with heterogeneously informed traders." Journal of financial economics 14.1: 71-100.

Goyenko, R. Y., Holden, C. W., Trzcinka, C. A., 2009. "Do liquidity measures measure liquidity?" Journal of financial Economics 92 (2), 153-181.

Jankowitscha, A., Nashikkarb, M. G. Subrahmanyamb, 2011. "Price dispersion in OTC markets: A new measure of liquidity", Journal of Banking \& Finance.

Joseph, A., Joseph, S. and Chen G., 2014, "Cross-border portfolio investment networks and indicators for financial crises". Scientific Reports 4, 3991.

Kyle, Albert S., 1985. "Continuous auctions and insider trading." Econometrica: Journal of the Econometric Society: 1315-1335.

Loon, Y. C., Zhong, Z. K., 2014. "The impact of central clearing on counterparty risk, liquidity, and trading: Evidence from the credit default swap market". Journal of Financial Economics 112 (1), 91-115.

Roll, R., 1984. "A simple implicit measure of the effective bid-ask spread in an efficient market", Journal of Finance.

Shleifer, A., Vishny, W., R., 1997. "The limits of arbitrage." The Journal of Finance 52.1, 35-55.

Stoll, Hans R., 1978. "The supply of dealer services in securities markets." The Journal of Finance 33.4: 1133-1151. 


\section{Appendix}

\section{Methodology for three tier network construction}

Segmentation of the market into three tiers is done by classifying nodes in the network using the degree distributions of the forwards and options networks. ${ }^{28}$ In Chart 27, the $x$-axis represents the number of connections a given counterparty has with other counterparties (i.e. the number of outstanding positions with different counterparties). The $y$-axis shows the fraction of counterparties which have a larger or equal number of connections, i.e. the inverse cumulative degree distribution. Both the forwards and options markets are characterised by a heterogeneous topology with a densely connected group of dealers at its centre (to the right of the vertical lines). At the other extreme around a fifth of counterparties have only one link. This distribution is stable over time and largely unaffected by the event.

This heterogeneous topology means the market is highly concentrated around high-degree nodes and liquidity provision relies on a small number of highly interconnected counterparties, that is, mainly dealer banks. This may make the network more vulnerable to shocks that affect any of these central counterparties, see Albert and Barabási (2002). Based on the observations that not all dealer banks are high-degree hubs in this network picture ${ }^{29}$ and that there is a high degree of heterogeneity between the remaining clients, we propose a topological three-tier classification of the market: Note that the three-tier structure is determined endogenously, i.e. by the properties of the market structure. Only the cut-off to distinguish between the inner and outer core has been set in a data-driven way.

- Inner core (red in Chart 12): All counterparties to the right of the vertical lines in Chart 27 (Chart 28 shows the corresponding picture for options). The cut-offs have been set before the 'scale-free-like' part of the distributional tails of the out-degree (number of CHF-short positions) distribution, which is stable at about 50-60 over the whole period for forwards and 10-20 for options. ${ }^{30}$ These nodes are the hubs, i.e. mostly connected counterparties, of the network and consist of a stable group of 11 dealer banks ${ }^{31}$.

- Outer core (blue in Chart 12): The largest strongly connected component of the network, excluding counterparties in the inner core. Every node in the outer core can be reached from every other node via a path of directed long/short positions. These are counterparties which have at least one short and one long position in EURCHF, which, for some counterparties, could mean they were engaging in market-making activity to some degree. These counterparties also can be classified by their degree, which lies between two and 55/15 for forwards/options.

- Periphery (green in Chart 12): The largest weakly connected component of the network, consisting of counterparties which are connected to the core, but have no

\footnotetext{
28 The degree (number of connections) distribution of a network is an indicator for its internal structure. The main distinction is made between homogeneous topologies, where most nodes have a comparable number of connections, and heterogeneous topologies, where the degree can vary over several orders of magnitudes and where, in most cases, there is a small fraction of interconnected hubs with a particularly high number of connections. The topology of a network has implications for a network's resilience under different attack/shock scenarios.

29 This may be related to the lack of data on the EURCHF market.

${ }^{30}$ Taking the in-degree or total (i.e. in -plus out-) degree leads to the same overall picture.

${ }^{31}$ Here we used the out-degree distribution, that is the number of aggregated CHF short-positions a counterparty has. The classification is broadly the same in composition and stability when using $\mathrm{CHF}$ long-positions. There is one smaller dealer in our dataset which may switch between the inner and outer core depending on the chosen cut-off (see Chart 12 and the second pie-chart in Chart 13).
} 
directed paths to or from all other counterparties. The periphery mostly consists of typical clients in the traditional two-tier picture, which only buy or sell a given currency, hence mostly having a single connection going in either direction.

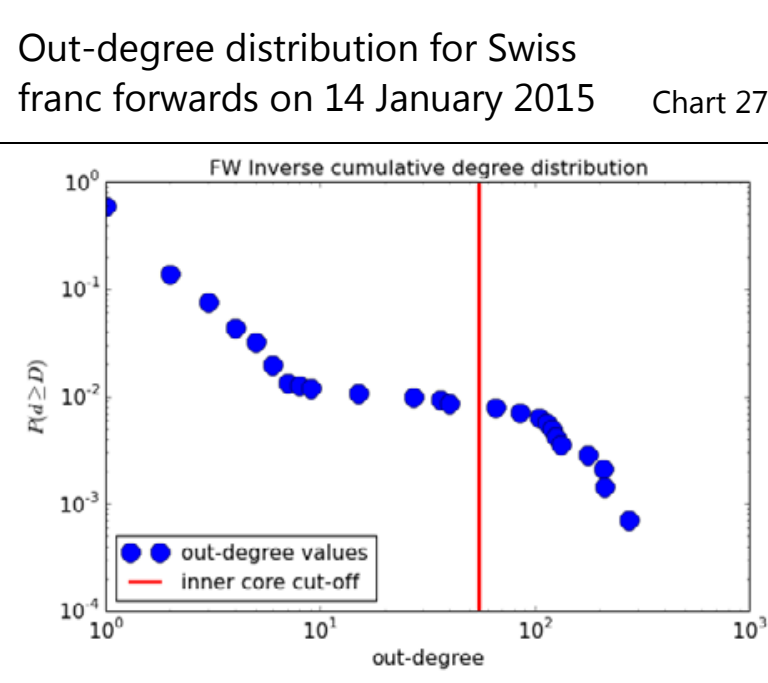

Source: DTCC and Bank calculations.
Out-degree distribution for Swiss franc options on 14 January 2015 Chart 28

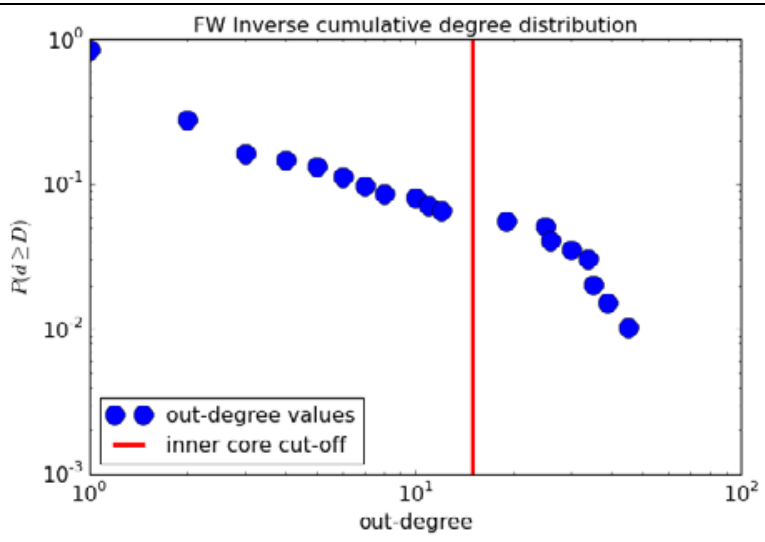

Source: DTCC and Bank calculations. 
Eighth IFC Conference on "Statistical implications of the new financial landscape"

Basel, 8-9 September 2016

\section{Gauging market dynamics using trade repository data: The case of the Swiss franc de-pegging ${ }^{1}$}

Ujwal Shreyas,

Bank of England

1 This presentation was prepared for the meeting. The views expressed are those of the author and do not necessarily reflect the views of the BIS, the IFC or the central banks and other institutions represented at the meeting. 


\section{Gauging market dynamics using trade repository data}

The case of the Swiss franc de-pegging

\section{Ujwal Shreyas}

8 September 2016 


\section{Agenda}

- Background

- The analysis of the 15 January 2015 de-pegging event.

- An intraday reconstruction of the event.

- Market structure - Three tier network

- Long term effects on liquidity, volatility and market fragmentation

- Conclusion

We are analysing the event, but are not commenting on the SNB's policy decision

The views expressed in this paper are those of the author(s), and not necessarily those of the Bank of England or its committees 


\section{Background - The SNB exchange rate policy overview}

- On 6 September 2011, SNB sets minimum exchange rate at CHF 1.20 per euro

"The current massive overvaluation of the Swiss franc poses an acute threat to the Swiss economy and carries the risk of a deflationary development." - SNB, 6 Sep 2011

- On 15 January 2015 at 9.30am UK time the SNB surprised the markets by announcing it was discontinuing the 1.20 EURCHF floor and also lowered interest rates on sight deposit account balances to $-0.75 \%$

"Recently, divergences between the monetary policies of the major currency areas have increased significantly ..... In these circumstances, the SNB concluded that enforcing and maintaining the minimum exchange rate for the Swiss franc against the euro is no longer justified." - SNB, 15 Jan 2015 


\section{Immediate impact of the SNB announcement on the FX spot \& forward prices}

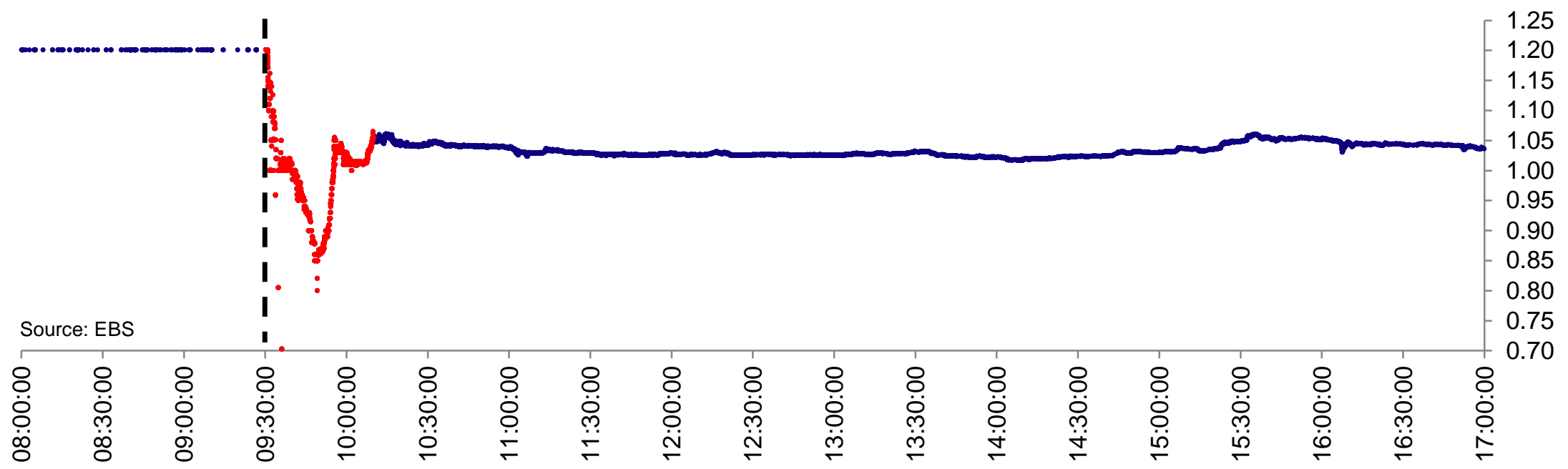

9:30 AM (UK Time) - SNB surprised the markets by discontinuing the 1.20 EURCHF floor

9:48 AM - Swiss franc(CHF) had an unprecedented $41 \%$ appreciation against euro

10:10 AM - CHF eased back and was up only 15\% from the pre-announcement level

Rest of the day - CHF stabilised and ended the day $14 \%$ higher against the euro 


\section{Immediate impact of the SNB announcement on the FX spot and forward prices}

Swiss francs per

- EURCHF trades $\quad \cdot 9.30-10.10 \mathrm{am}$

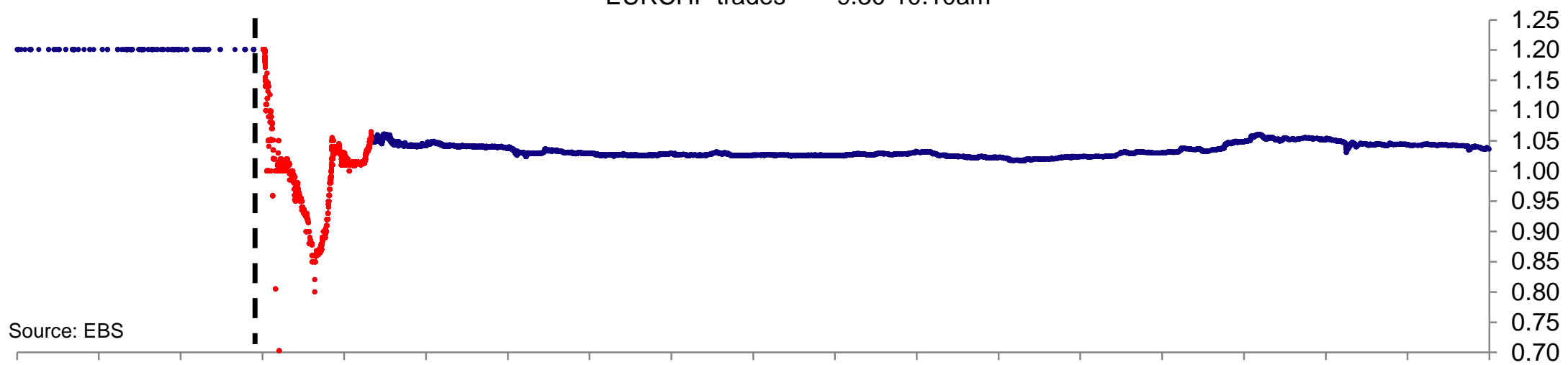

Swiss francs per

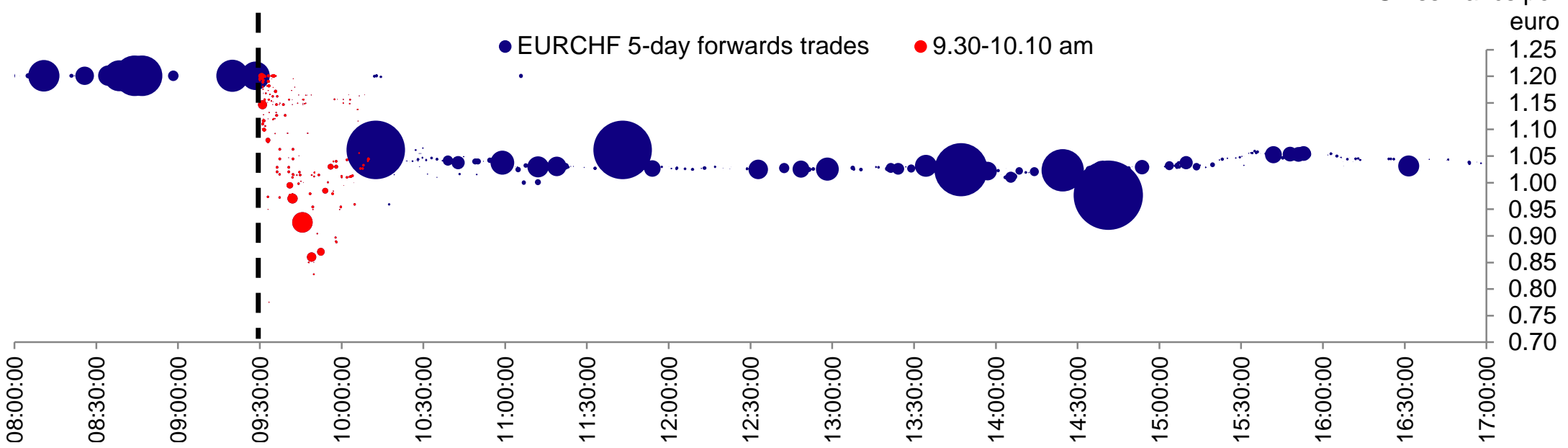




\section{Reconstructing the SNB event}

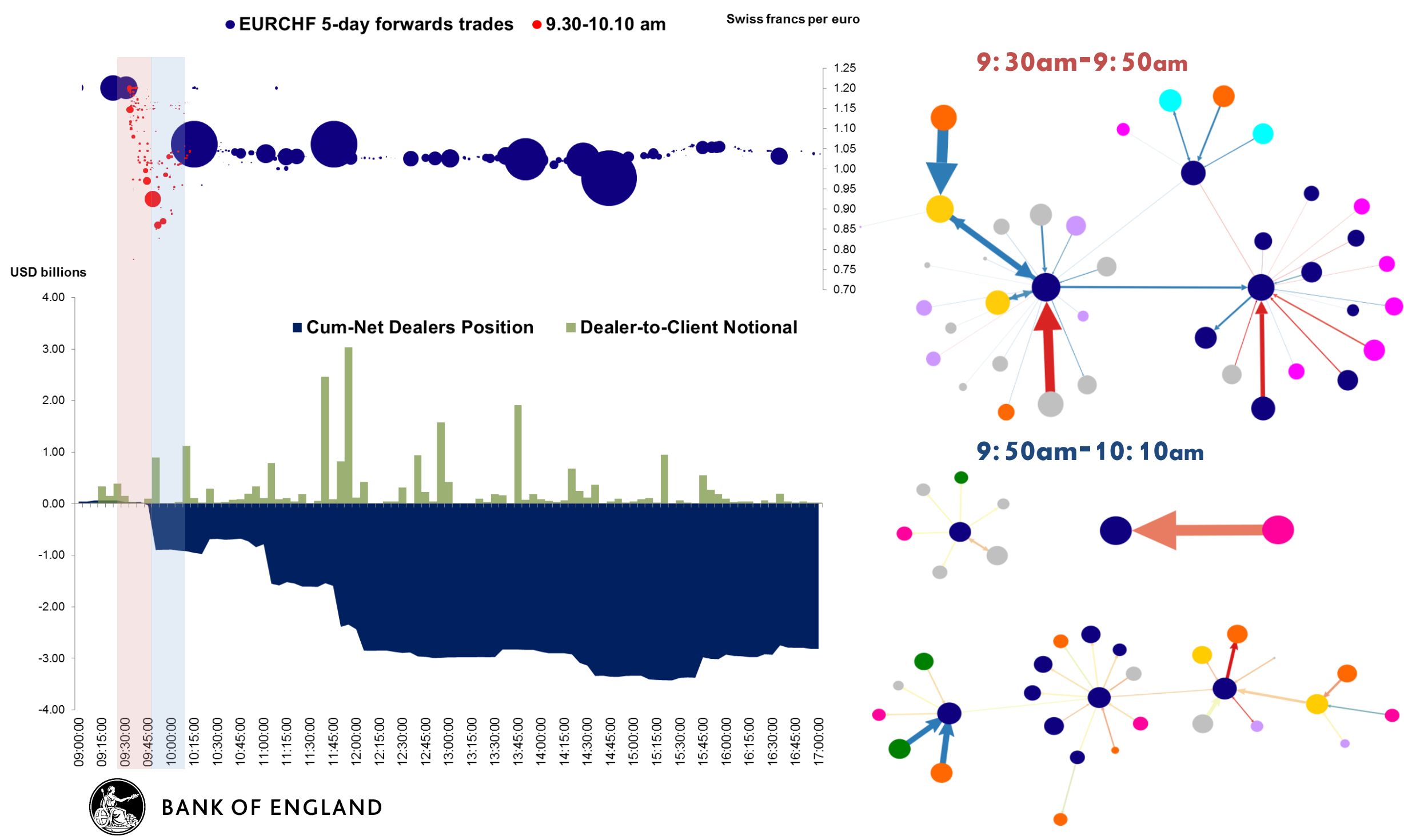




\section{Reconstructing the SNB event}

- EURCHF 5-day forwards trades $\bullet 9.30-10.10$ am

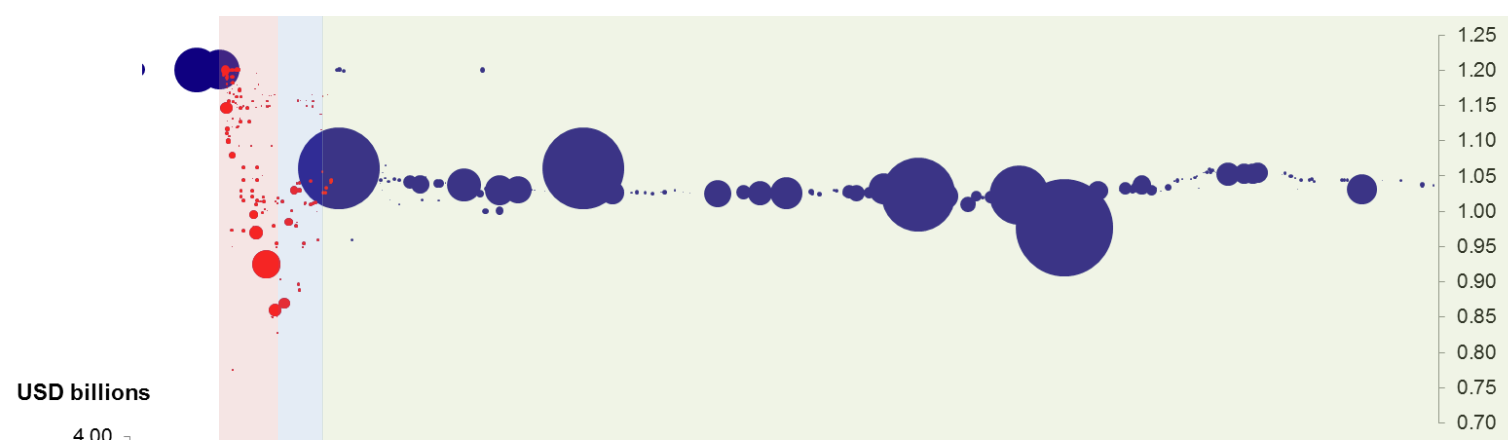

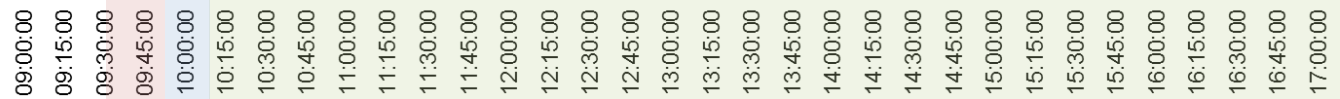

BANK OF ENGLAND

\section{$9: 30 \mathrm{am}=9: 50 \mathrm{am}$}

- There was limited dealer-client activity between 9:30-9:50 $\rightarrow$ Approx. \$300ml.

- Dealers were actually initially buying Swiss francs, which indicates that they were consuming liquidity instead of providing it.

- $\quad$ The average trade size of EURCHF forwards trades was very low.

$$
\rightarrow \text { EURCHF price collapsed. }
$$

\section{9:50am-10:10am}

- $\quad$ Client-side started selling $\mathrm{CHF} \rightarrow$ Dealers bought at 0.92 .

- Dealers were willing to trade at very

unfavourable prices, buying Swiss franc below parity.

- $\quad$ Client-side was mainly small banks.

$$
\rightarrow \text { EURCHF price reverses at } 1.05 \text {. }
$$

\section{After 10:10am}

- Trading conditions improved.

- Dealers remained net buyers.

$$
\rightarrow \text { Prices stabilised }
$$




\section{Market Structure: EURCHF forward market}

Using the degree distribution property of the network we can classify the counterparties as:

Inner core: These nodes are the topological hubs of the network and consist of a stable group of dealer banks.

Outer core: These counterparties have at least one short and one long position in EURCHF, which could mean they were engaging in market-making activity to some degree.

Periphery: The periphery mostly consists of the typical client in the more traditional 2-tier picture, as it only goes long or short on one currency.

\section{Implications of the three tier network structures:}

- The three-tier classification may be helpful for assessing which firms are particularly important to the functioning of a given market. A firm is classified as being part of the 'outer core' rather than 'periphery' may suggest it is more central to the stability of the network
Outstanding derivatives gross exposures (14.1.2015)

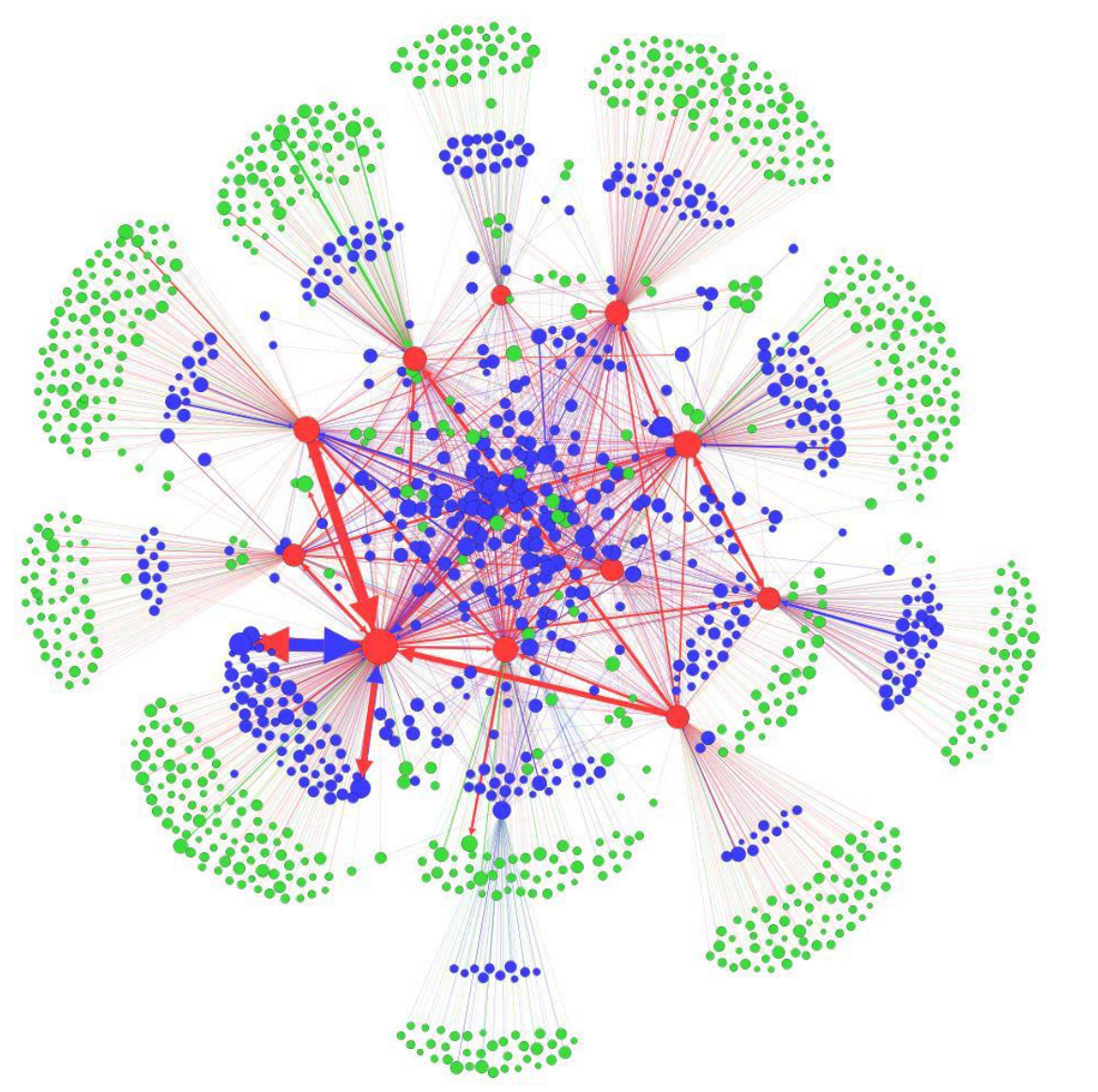




\section{Increase in volatility, price dispersion and illiquidity}

Realised variance and price dispersion

_ Realised variance (RHS)

- Price dispersion (LHS)

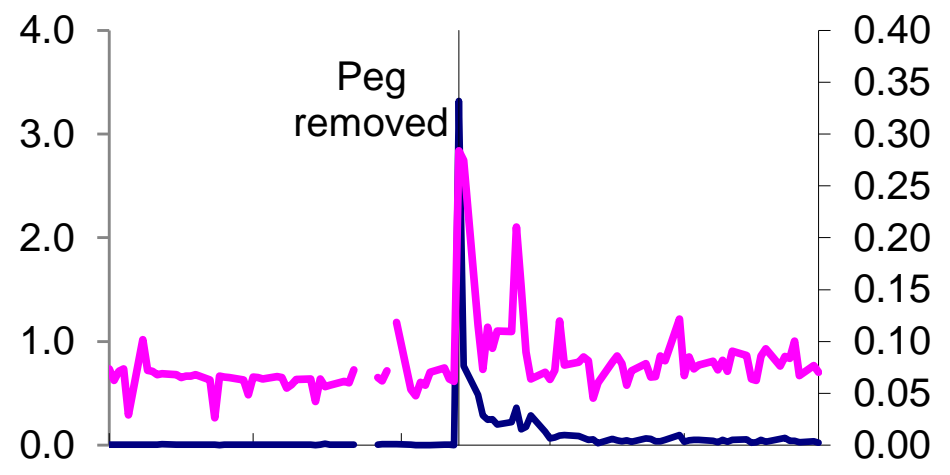

Nov-14 Dec-14 Jan-15 Feb-15 Mar-15

- Measures of volatility, price dispersion and illiquidity rose on 15 January and remained elevated in the aftermath

- $\quad$ Persistent drop in average trade size in EURCHF and EURUSD derivatives
Roll measure of illiquidity

-Roll measure

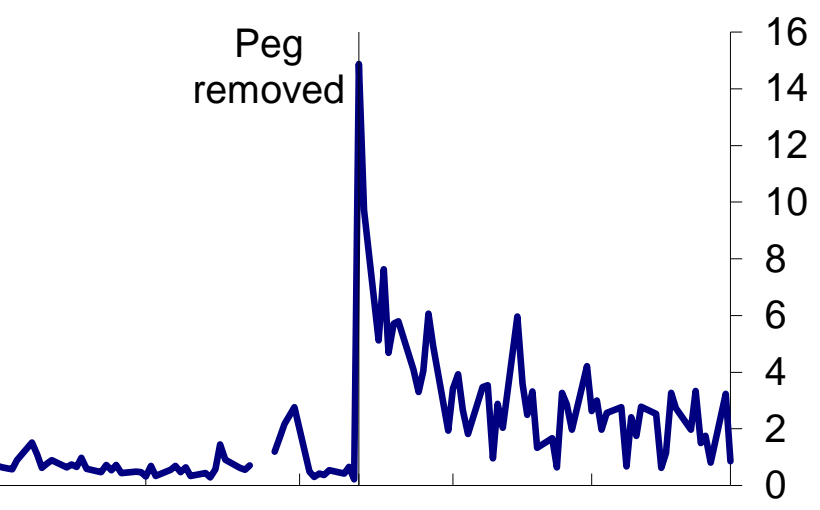

Nov-14 Dec-14 Jan-15 Feb-15 Mar-15

\section{Average trade size}

- Average pre-15 Jan 15 Jan 2015

- Average post-15 Jan

USD millions

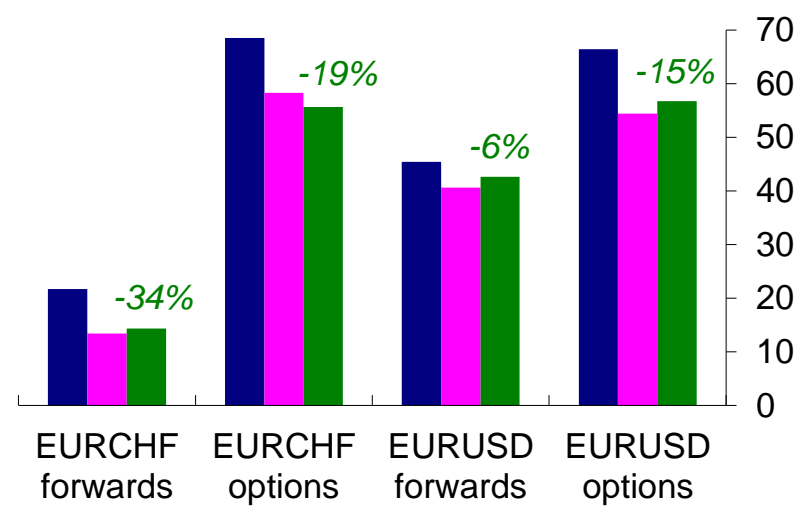




\section{Increase in market fragmentation post 15 January announcement}

$\underline{\text { Increase in market fragmentation }}$

Connected components

- - -Average pre-SNB

- - Average post-SNB $\quad[10$

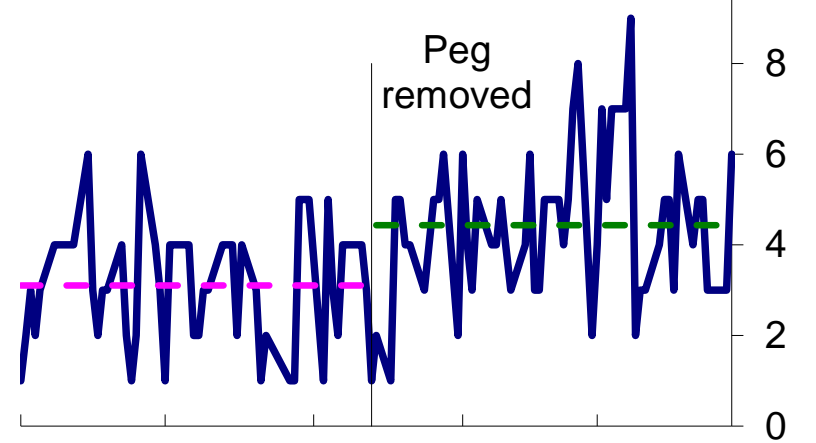

Nov-14 Dec-14 Jan-15 Feb-15 Mar-15

15 January 2015
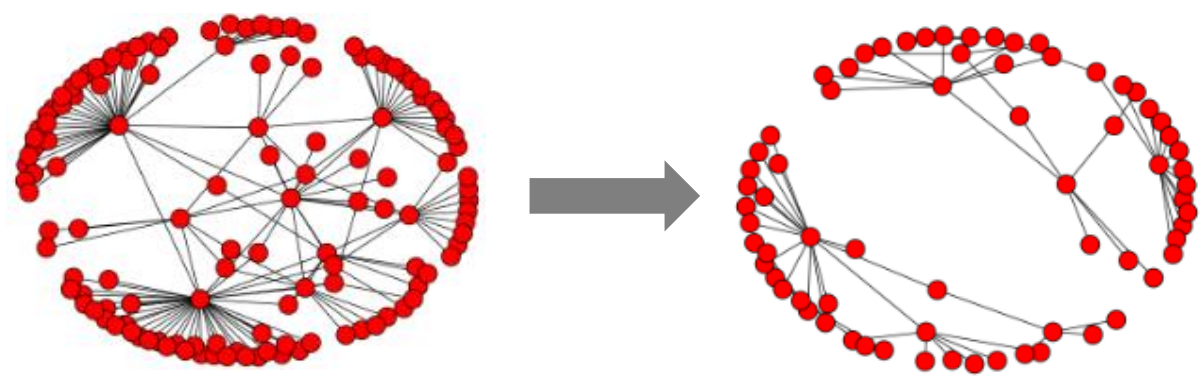

Decrease in dealer-to-dealer links

Fraction of dealer-to-dealer links

- Average pre-SNB

- - Average post-SNB

Percent

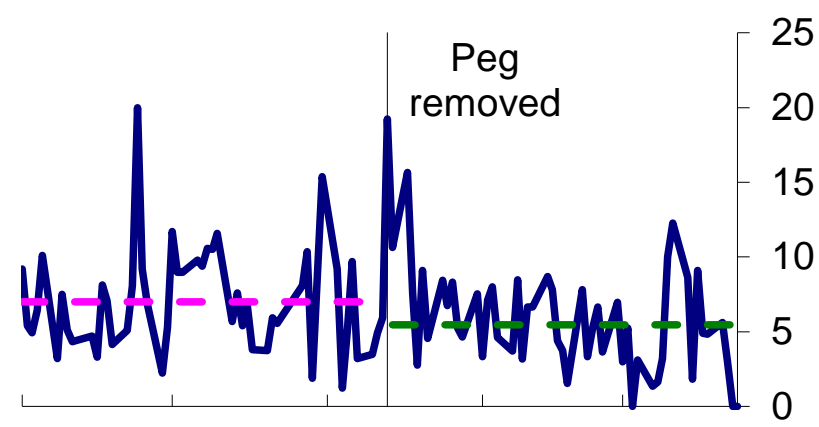

Nov-14 Dec-14 Jan-15 Feb-15 Mar-15

- More decentralised market:

- Increase in number of components in CHF market

- Lower proportion of inter-dealer links

- Decrease in link density 


\section{Conclusion}

- First in-depth and large-scale study of the FX derivatives market using trade repository data resulting from the EMIR reporting framework In the event analysis we find:

- Rapid V-shaped price movement in the EURCHF OTC forward market similar to the one observed in the spot market

- In the first 15 minutes after the announcement, the provision of liquidity was limited

- After 15 minutes, dealers gradually started to play the role of liquidity provider, even if this activity was potentially loss-making as it coincided with the Swiss franc price reversal (i.e. depreciation).

- In the longer term we find that: a) the trading network became more fragmented b) liquidity in the market decreased, 


\section{Questions?}

\section{Contacts}

olga.cielinska@bankofengland.co.uk andreas.joseph@bankofengland.co.uk

ujwal.shreyas@bankofengland.co.uk john.tanner@bankofengland.co.uk michalis.vasios@bankofengland.co.uk 